\title{
Rediscovering the octapeptins
}

\author{
Tony Velkov ${ }^{1,{ }^{*}}$, Kade Roberts ${ }^{1,2}$, and Jian $\mathrm{Li}^{2,{ }^{*}}$ \\ ${ }^{1}$ Drug Development and Innovation, Drug Delivery, Disposition and Dynamics, Monash University, \\ VIC, 3800, Australia \\ ${ }^{2}$ Monash Biomedicine Discovery Institute, Department of Microbiology, Monash University, VIC, \\ 3800, Australia
}

\begin{abstract}
The decline in the discovery and development of novel antibiotics has resulted in the emergence of bacteria that are resistant to almost all available antibiotics. Currently, polymyxin B and $\mathrm{E}$ (colistin) are being used as the last-line therapy against life-threatening infections, unfortunately resistance to polymyxins in both the community and hospital setting is becoming more common. Octapeptins are structurally related non-ribosomal lipopeptide antibiotics that do not exhibit crossresistance with polymyxins and have a broader spectrum of activity that includes Gram-positive bacteria. This makes them a precious and finite resource for the development of new antibiotics against these problematic polymyxin-resistant Gram-negative pathogens, in particular Pseudomonas aeruginosa, Acinetobacter baumannii and Klebsiella pneumoniae. This review surveys the progress in understanding octapeptin chemistry, mechanisms of antibacterial activity and biosynthesis. With the lack of cross-resistance and their broad antibacterial activity, the octapeptins represent ideal candidates for the development of a new generation of polymyxin-like lipopeptide antibiotics targeting polymyxin-resistant 'superbugs'.
\end{abstract}

\section{Keywords}

Octapeptin; polymyxin; lipopolysaccharide; lipid A; structure activity relationships; resistance; mechanism; pharmacology

\section{Octapeptins, a forgotten antibiotic discovery}

In recent times the world has seen the emergence of bacteria that are resistant to almost all available antibiotics. ${ }^{1,2}$ Over the last 30 years only two novel antibiotic classes have been introduced into the clinic (linezolid and daptomycin), illustrating that the golden era of antibiotic discovery is well and truly over. ${ }^{3,4}$ Many pharmaceutical companies have lost interest in producing new antibiotics, preferring to focus on the development of more profitable products for the treatment of chronic conditions and lifestyle issues. Thus, there has been a decline in the discovery and development of novel antibiotics, and as a result we have seen the increasing global emergence of extremely resistant (XDR) 'superbugs', a dire

\footnotetext{
“Corresponding author: Jian.Li@monash.edu OR Tony.Velkov@monash.edu.
} 
situation has been dubbed the 'perfect storm' ${ }^{3,4}$ The World Health Organization identifies antimicrobial resistance as one of the greatest threats to human health. ${ }^{2,5,6}$

In the 1970s the therapeutic use of polymyxins declined due to their nephrotoxicity as well as introduction of alternative antibiotics such as the $\beta$-lactams that were considered safer than polymyxins at that time. ${ }^{7-9}$ However, the exhaustive use of the $\beta$-lactam antibiotics has led to wide-spread resistance, leaving only very limited therapeutic options available to clinicians. ${ }^{10-13}$ Polymyxin B and colistin are now being increasingly used, especially in critically-ill patients as last-line therapy. ${ }^{2-7}$ Resistance to polymyxins can rapidly emerge in vitro to $P$. aeruginosa, A. baumannii and $K$. pneumonia. ${ }^{2-7}$ Moreover, polymyxin resistance in community and nosocomial acquired infections is being increasingly reported and even more worrying is the emergence and spread of MCR-1 plasmid borne polymyxin-resistance.

${ }^{14}$ Unfortunately polymyxin resistance indicates a total lack of treatment options for problematic Gram-negative infections. Therefore, there is an urgent unmet medical need to develop new and safer lipopeptide antibiotics. The problematic Gram-positive Enterococcus faecium and $\underline{S}$ taphylococcus aureus together with XDR Gram-negative bacteria $\underline{P}$.

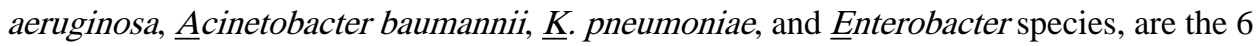
top-priority dangerous ESKAPE 'superbugs' identified by Infectious Diseases Society of America as requiring the most urgent attention for discovery of novel antibiotics. ${ }^{8}$

The octapeptins are a family of naturally occurring cyclic lipopeptide antibiotics with broad antimicrobial spectrum against polymyxin-resistant Gram-negative and Gram-positive bacteria. The approaching 'perfect storm' of bacteria that are resistant to all available antibiotics combined with the dry antibiotic pipeline means that that the time has come to revisit these 'forgotten' antibiotics with 'new potential'. Although octapeptins were discovered over 40 years ago there is very little coverage of them in the literature and they were discovered before the establishment of contemporary drug development processes. Consequently, a lot of work remains to be done as their mode of action, pharmacology and toxicity remains, largely uncharacterized. This review surveys the literature knowledge-base for the octapeptins in relation to the clinically used polymyxin lipopeptides. An emphasis is placed on the development of octapeptins as a potential new generation of lipopeptide antibiotics for targeting polymyxin-resistant 'superbugs'.

\section{Chemical structures and nomenclature}

The octapeptins were originally isolated, from the soil bacteria Bacillus circulans. ${ }^{9-14}$ Like the polymyxins they are produced by bacteria as mixtures of structurally related peptides. To date 19 octapeptins have been isolated and characterized (Table 1). The octapeptins scaffold consists of a cyclic heptapeptide ring linked to a D-amino acid at position 1 and an $\mathrm{N}$ terminal $\beta$-hydroxyl fatty acyl tail (Figure 1). The $N$-terminal hydroxyl-fatty acyl group varies in length from $\mathrm{C}_{8}$ to $\mathrm{C}_{10}$ across the different octapeptins and can be non-branched (3$(R)$-hydroxydecanoic acid) or branched $((R)$-3-hydroxy-( $S)$-6-methyloctanoyl, 3- $(R)$ hydroxy-8-methyl-nonanoic acid, 3-( $R$ )-hydroxy-8(S)-methyldecanoic acid) fatty acyl chain. They contain 3-4 L-a, $\gamma$-diaminobutyric acid (Dab) residues; which make the octapeptin molecule a polycation at $\mathrm{pH}$ 7.4. Structural variation amongst the octapeptins is conserved to the structure of the $N$-terminal of the $\beta$-hydroxy-fatty acid and the structure and/or chirality 
of the amino acids presented at positions 1, 4 and 5 (Table 1). Before the nomenclature 'octapeptin' was coined, these lipopeptides were originally given the company codes Bu-2470, EM49, 333-25 and Bu-1880 or known as circulins/battacins by the teams from the pharmaceutical firms Squibb and Bristol-Myers. ${ }^{11-14}$ Eventually a consensus on nomenclature was reached and the octapeptins were alphabetically designated into four groups; Octapeptins A-D based on the combination of amino acid residues presented at positions 1, 4 and 5 of their scaffold. (Table 1). ${ }^{10}$ Further designation was given to individual lipopeptides within these groups by placing a subscripted number after the designated letter of the group. Individual lipopeptides within a group are differentiated by the structure of their $N$-terminal fatty acyl group (Table 1 ).

\section{Octapeptins and polymyxins: chalk and cheese or peas in a pod?}

In terms of similarities, polymyxins and octapeptins are both cyclic lipopeptides characterized by a high proportion of positive Dab residues in their sequence. Both polymyxins and octapeptins have a cyclic heptapeptide core linked to an $N$-terminal fatty acyl chain (Figure 1). Both octapeptin and polymyxins possess a hydrophobic motif in their cyclic heptapeptide ring (positions 4 and 5 for octapeptins; positions 6 and 7 for polymyxins). ${ }^{15}$ However there are several notable structural differences between the polymyxins and the octapeptins The exo-cyclic side chain of the octapeptins is invariably a single D-amino acid (D-Dab or D-Ser), whereas in the polymyxins the side chain consists of a tri-peptide segment, with all amino acids residues usually of the L-configuration; except for polymxyins A, D and $\mathrm{P}$, which display either D-Dab or D-Ser at position 3 (position 1 in the octapeptins). In the octapeptin cyclic hepta-peptide ring a hydrophobic L-Leu residue is found at position 8, whereas the equivalent residue in the polymyxins (position 10 in polymyxins) is a hydrophilic L-Thr. The length of the $N$-terminal fatty acyl chains also differ, with the octapeptins displaying longer $\mathrm{C}_{9}$ or $\mathrm{C}_{10} \beta$-hydroxyl fatty acyl chains as opposed to the shorter $\mathrm{C}_{7}$ or $\mathrm{C}_{8}$ fatty acyl chains of polymyxins which also lack a $\beta$ hydroxyl group (polymyxin $\mathrm{B}_{1}$ and colistin $\mathrm{A}$ : 6-(S)-methyloctanoyl; polymyxin $\mathrm{B}_{2}$ and colistin B: 6-methylheptanonyl). ${ }^{16-25}$ Notably, polymyxin $\mathrm{B}_{6}$ is unique in that it's the only polymyxin that has a fatty acyl chain containing a 3-hydroxy group. ${ }^{15}$ Octapeptins and polymyxins also differ in their charges as a result of the reduced number Dab residues due to the truncated linear segment; octapeptins possess 3-4 positive charges, whereas the polymyxins possess 4-5 positive charges. All of these structural differences increase the overall hydrophobicity of the octapeptins relative to the polymyxins. Furthermore in the octapeptins the chirality of the amino acid residues found at positions 4 and 5 of the cyclic hepta-peptide ring (positions 6 and 7 in the polymyxins) can vary between the different octapeptin groups where as in the polymyxins the chirality is conserved across the different groups.

\section{Antibacterial activity}

Fundamentally, the octapeptin molecule can be considered as being a truncated polymyxin molecule, albeit, this compact package packs a powerful punch with superior activity against polymyxin-resistant pathogens and Gram-positive bacteria (Table 2). Not unlike the polymyxins the octapeptins are outer membrane $(\mathrm{OM})$ active antibiotics with biocidal 
activity against Gram-negative bacteria. ${ }^{14}$ However, unlike the polymyxins which have a narrow spectrum of activity solely against Gram-negative bacteria, octapeptins exhibit a broader spectrum of activity that also includes Gram-positives, yeast, filamentous fungi and protozoa (Table 2). ${ }^{16,17,26-31}$ Most importantly, octapeptins do not display cross-resistance with polymyxins against Gram-negative bacteria; this is potentially owing to a unique mode of action. Interestingly, the octapeptins generally display reduced activity against polymxyin-susceptible Gram-negative isolates. ${ }^{16,17,26-30}$ Notably, neither the polymyxins nor octapeptins are active in vitro against Serratia marcescens and Proteus spp., presumably due to the unique lipid A structures of these species. ${ }^{27,}$, $32-34$ The addition of human serum $(25,50$ or $75 \%)$ does not impact the in vitro antibacterial activity of octapeptins. ${ }^{27,34}$ Octapeptins have also been shown to possess potent antipseudomonal biofilm activity. ${ }^{35,36}$

Encouragingly, attempts to develop resistance to octapeptins in vitro were unsuccessful when sub-culturing of Escherichia coli, $P$. aeruginosa and $S$. aureus through ten successive transfers in the presence of octapeptin A (EM49). ${ }^{37}$ However, an inoculum effect was evident against E. coli, $P$. aeruginosa and $S$. aureus, as octapeptins were less active at higher inoculums sizes. ${ }^{27,} 34$ In vivo experiments using a mouse blood infection model showed that the octapeptin A, when administered subcutaneously at $18.7 \mathrm{mg} / \mathrm{kg}$ and $110-130 \mathrm{mg} / \mathrm{kg}$, protected mice from E. coli and Streptococcus pyogenes, respectively. ${ }^{37}$ The octapeptin A was inactive following oral administration. ${ }^{37} \mathrm{~A} 0.5 \%$ cream based formulation of the octapeptin A was also demonstrated to be effective in a $P$. aeruginosa wound infection model. ${ }^{37} \mathrm{An}$ in vivo study by the Bristol-Myers Company using an interperitoneal mouse infection model showed that octapeptins $\mathrm{C}_{0}(\mathrm{Bu}-2470 \mathrm{~A}), \mathrm{C} 2\left(\mathrm{Bu}-2470 \mathrm{~B}_{1}\right)$ and $\mathrm{C} 3 / \mathrm{C}_{4} \mathrm{~B}_{2}$ protected mice from lethal challenge by E. coli, P. aeruginosa and $K$. pneumoniae at intramuscular doses of 7.6-25 mg/kg octapeptin $\mathrm{C}_{0}, 43-100 \mathrm{mg} / \mathrm{kg}$ (octapeptin $\mathrm{C}_{2}$ ) and 22 $\mathrm{mg} / \mathrm{kg}$ (octapeptin $\mathrm{C}_{3}$; octapeptin $\mathrm{C}_{3}$ was inactive against E.coli and $K$. pneumoniae. Notably, octapetin $\mathrm{C}_{0}$, which is des-fatty acyl octapeptin (i.e has the $N$-terminal $\beta$-hydroxyl fatty acyl removed) was more active in vivo than in vitro compared to octapeptin $\mathrm{C}_{2}$ and octapetin $\mathrm{C}_{3} \mathrm{~B}_{2}$ which have an intact $\beta$-hydroxyl decanoyl fatty acyl terminus. ${ }^{27,} 34$ This finding would suggest that the $N$-terminal $\beta$-hydroxyl fatty acyl can impact the pharmacokinetics of octapeptins, possibly by increasing the plasma protein binding. Another in vivo study from the Bristol-Myers Company also using the same interperitoneal mouse infection model showed that octapeptin $\mathrm{Bu}-1880$ protected mice from a lethal challenge of E. coli, $P$. aeruginosa and $S$. aureus at subcutaneous doses of 165,100 and $80 \mathrm{mg} / \mathrm{kg}$, respectively. ${ }^{31}$ The study employed colistin as the comparator, which showed superior protection against E. coli $(3.4 \mathrm{mg} / \mathrm{kg})$, P. aeruginosa $(15 \mathrm{mg} / \mathrm{kg})$, but not surprisingly was inactive against $S$. aureus. ${ }^{31}$ A more recent in vivo study with octapeptin $\mathrm{B}_{5}$ dosed intravenously at $4 \mathrm{mg} / \mathrm{kg}$ provided 90 and $100 \%$ protection of mice challenged with lethal doses of E.coli ATCC 35318 and E. coli 5539, respectively. ${ }^{38}$

\section{Mechanism of action}

In light of the fact that there is limited information on the mode of action of octapeptins; and given their structural similarities with the polymyxins, it is pertinent to mention our current understanding of the mode of action of polymyxins. Polymyxins are believed to exert their primary antimicrobial mode of action by permeabilizing the Gram-negative bacterial outer 
membrane via a direct interaction with the lipid A component of the lipopolysaccharide (LPS) (Figure 2). Not unlike the octapeptins, the polymyxins are amphipathic in nature due to a hydrophobic $N$-terminal fatty acyl chain and the polar and cationic residues that constitute their structure. The disruptive effect of polymyxins on the outer membrane is thought to involve a two stage interaction mechanism with the lipid A component of LPS. In stage one, it is purported that the cationic side-chains of the $5 \mathrm{Dab}$ residues on the polymyxin molecule electrostatically bind to the anionic phosphate groups on the lipid A core; thereby displacing the divalent cations that normally bridge adjacent lipid A molecules and serve to maintain membrane integrity. ${ }^{39-44}$ Not surprisingly, the most common resistance mechanism against polymyxins that Gram-negative bacteria employ is to modify their lipid A phosphate groups with positively charged groups such as ethanolamine or $4^{\prime}$ aminoarabinose, which acts to abolish the initial electrostatic interaction. ${ }^{45-50}$ This initial electrostatic stabilizing interaction allows the $N$-terminal fatty acyl chain of the polymyxin molecule to insert into the hydrocarbon layer of the lipid A molecules. Evidence in support of this mechanism is the observation that des-fatty acyl polymyxin nona-peptide (which lacks the $N$-terminal fatty acyl chain through enzymatic removal) does not have any bactericidal activity and is only bacterisostatic. ${ }^{51,52}$ Intriguingly, the same cannot be said for des-fatty acyl octapeptins, this topic is discussed further in the following SAR section. This suggests that it is a combination of the stage one electrostatic and stage two hydrophobic interactions that are crucial for the mode of action of polymyxins. Subsequent events remain unclear, however, a 'self-promoted' up-take mechanism is believed to produce disruption of the outer membrane structure, and gives the lipopeptide access to the cytoplasmic membrane. ${ }^{40-44}$ An early mechanistic ${ }^{32}$ P NMR study by Stephen Fesik at Abbott Labs revealed that octapeptins have the ability to bind to lipid A, particularly to the ethanolamine or $4^{\prime}$-aminoarabinose modified lipid structures seen in polymyxin resistant strains. ${ }^{53}$ This finding suggests that unlike polymxyins that primarily target lipid A and show poor affinity for phospholipids, the octapeptins retain the ability to avidly bind both of these core lipids; which could help explain their extended spectrum of activity against Gram-positives, that lack LPS in their outer membrane. ${ }^{23}$ Notably, similar to the polymyxins, octapeptins have been shown to disrupt the normal electrostatic interactions between divalent cations and lipid A that stabilize the outer membrane, this mechanism is supported by the specific protection of Gram-negatives against octapeptins afforded by $\mathrm{Mg}^{2+}$ and $\mathrm{Ca}^{2+.23,38}$

What is known about the primary mode of action of octapeptins is that they bind to bacterial phospholipids and perturb the outer membrane structure, which helps explain their broad activity. ${ }^{30}$ Since octapeptins are amphipathic in character, at first glance it may be assumed that their disruptive influence on the bacterial outer membrane can be attributed to an activity akin to that of a simple cationic detergent. However, this is not the case as octapeptins exhibit bactericidal activity at much lower concentrations than simple cationic detergents and moreover, they display dose-dependent activity. ${ }^{16-19}$ Furthermore, minor structural modifications to the octapeptin core scaffold produce significant changes in their bactericidal activity. ${ }^{30,54}$ Taken together, these findings highlight that there are specific interactions between the octapeptin molecule and the bacterial outer membrane that are at play. Scanning and transmission electron microscopy revealed that $E$. coli cells treated with octapeptin A caused the formation of numerous protrusions or blebs extending from the 
outer membrane of the cells. ${ }^{23}$ The composition of the blebs was shown to be outer membrane fragments. ${ }^{18,23,30}$ Furthermore it was shown that octapeptin treatment rapidly stimulated the release of membrane vesicles from the cells into the surrounding media, further indicating this was not the result of a secondary event. ${ }^{18,}{ }^{30}$ Notably, a similar blebbing effect was observed with Gram-negative bacterial cells treated with polymyxin B and colistin. ${ }^{55}$ The cytoplasmic membrane permeabilizing effect of octapeptins has also been demonstrated by their ability to produce potassium release, proton leakage and an enhanced uptake of fluorescent membrane probes. ${ }^{23,} 30,35,38$ A recent report also showed octapeptin B5 has a depolarizing effect on the cytoplasmic membrane of $P$. aeruginosa ATCC 27853 cells, albeit, the effect somewhat weaker than that of polymxyin B. ${ }^{38}$ So it follows, we can conclude the ability of octapeptins to disrupt the other membrane of Gramnegative bacteria is somewhat akin to that of the polymyxins. The characterization of octapeptin interactions with bacterial membranes using spin-labeled octapeptin probes suggested that the $\beta$-hydroxyl fatty acyl chain of the octapeptin inserts into the hydrocarbon domain of lipid bilayers. ${ }^{56}$ Furthermore, spectral analysis of the spin-labeled octapeptin showed the $\beta$-hydroxyl fatty acyl chain interacts with the position 4 and 5 hydrophobic motif (D-Leu/D-Phe - P5 L-Leu) in the solution configuration; suggesting the octapeptin structure forms a hydrophobic triad that penetrates the bacterial membrane. ${ }^{56}$

In terms of a secondary mode of action, the octapeptins appear to interfere with a range of biochemical processes in both Gram-positive and Gram-negative bacteria such as respiration, selective membrane ion transport, ATP pool size and miscellaneous inner membrane enzyme-catalyzed activities. ${ }^{22,30,57}$ However, it remains unknown which of these secondary effects result from the aforementioned primary outer membrane lesions. ${ }^{30}$ Coincidently, our group demonstrated that a secondary mode of action of polymyxin B and colistin against Gram-negatives involves inhibition of a key bacterial respiratory chain inner membrane enzyme, NADH-quinone oxidoreductase. ${ }^{58}$

Overall, although octapeptins appear to have mechanistic similarities with polymxyins, their broad spectrum of activity and ability to avidly bind phospholipids perhaps attests to a unique mode of action

\section{Structure Activity Relationships}

To date most of the available SAR data for octapeptins has focused around the $N$-terminus. 27, 34-36 The early work from the Bristol-Myers Company showed that des-fatty acyl octapeptin $\mathrm{C}_{0}$ lost all in vitro antibacterial activity against Gram-positives, but retained appreciable activity against Gram-negatives species. ${ }^{27,} 34$ Interestingly, the des-fatty acyl octapeptin $\mathrm{C}_{0}$ showed superior in vivo activity against Gram-negatives than its counterparts octapeptins $\mathrm{C}_{2}$ and $\mathrm{C}_{3}$ which are contain an $N$-terminal $\beta$-hydroxyl fatty-acyl groups. ${ }^{27,} 34$ Similarly, a more recent study reported that a synthetic des-fatty acyl octapeptin $\mathrm{B}_{5}$ retained comparable in vitro antipseudomonal activity as its fatty acylated counterpart, albeit, Grampositive activity against $S$. aureus was once again abolished. ${ }^{35}$ The substitution of the $\beta$ hydroxyl fatty acyl with a series of $\mathrm{C}_{2}$ to $\mathrm{C}_{18}$ straight chain fatty acids revealed that the ideal $N$-terminal chain length for octapeptin activity against $E$. coli was $\mathrm{C}_{8}$ to $\mathrm{C}_{10}$, whereas the ideal chain length for activity against Bacillus subtilis was $\mathrm{C}_{12}$ to $\mathrm{C}_{16}{ }^{56}$ The substitution of 
the $N$-terminus of octapeptin $\mathrm{B}_{5}$ with a $\mathrm{C}_{6} 4$-methylhexanoyl or Fmoc group did not impact its activity against Gram-negatives, however, the Fmoc substituted analogue showed a marked improvement in activity against Gram-positives. ${ }^{35}$ In contrast the substitution of the $N$-terminus of octapeptin $\mathrm{B}_{5}$ with a $\mathrm{C}_{8}$ geranyl (3,7-dimethyl-2,6-octadien-1-yl acetate) or $\mathrm{C}_{14}$ myristyl chain abolished all antibacterial activity. ${ }^{35}$ Collectively these results suggest that the ideal chain length for antibacterial activity is in the range of $\mathrm{C}_{8}$ to $\mathrm{C}_{10}$, hydrophobicity at the $N$-terminus is also critical for activity against Gram-positives and the $\beta$-hydroxy group on the $N$-terminal fatty acyl is dispensable.

As covered in the preceding mode of action discussions the 5 cationic Dab residues are crucial for the antibacterial mode of action of the polymxyins. ${ }^{15}$ Not surprisingly, the cationic charge and exact side-chain length of the 4 Dab residues in the octapeptin sequence are also critical, as substitution with Ala or Lys residues leads to a marked decrease in antibacterial activity. ${ }^{35}$ More specifically, Ala screening studies revealed that the Dab residues at positions 1,3 and 6 are absolutely critical, whereas those at positions 2 and 7 are less important for antibacterial activity. ${ }^{35}$

The indispensability of the D-Phe/D-Leu-Leu hydrophobic motif at positions 6 and 7 for the antibacterial activity of the polymyxins is well known. ${ }^{15}$ Similarly, Ala scanning studies with octapeptin $\mathrm{B}_{5}$ showed that the corresponding motif at positions 4 and 5 of the octapeptin scaffold is also indispensible. ${ }^{35}$ Notably, the same study showed that Ala substitution of the invariable position 8 Leu of octapeptins (position $10 \mathrm{Thr}$ in polymxyins) does not markedly impact antibacterial activity, suggesting this position is a good target for regio-selective modification. ${ }^{35}$ The position 4 D-Phe/D-Leu and position 5 L-Phe/L-Leu variations seen across the naturally occurring octapeptins do not appear to noticeably impact antibacterial activity. ${ }^{20,30,54,59}$ The recent discovery of octapeptin $\mathrm{B}_{5}$ which has D-Phe at position 5 instead of L-Leu is fascinating as this is the first example of a polymxyin-like lipopeptide with the order of the D-Phe/D-Leu - L-Leu motif reversed. ${ }^{38}$ Octapeptin $\mathrm{B}_{5}$ showed MICs ranging from $2-8 \mathrm{mg} / \mathrm{L}$ against $P$. aeruginosa, $A$. baumannii and $K$.

pneumoniae, whereas the MICs for polymyxin B ranged from $0.5-2 \mathrm{mg} / \mathrm{L}$; both lipopeptides were in active against the $S$. aureus and E. faecalis strains tested (Table 2). ${ }^{38}$ These finding suggest the unusually position $5 \mathrm{D}$-Phe substitution does not impact antibacterial activity against Gram-negatives, but appears to decrease activity against Gram-positives.

Unlike polymyxins, where the cyclic structure is critical for antibacterial activity, ${ }^{15}$ linear octapeptins have been show to retain comparable in vitro antibacterial activity to their cyclic forms. ${ }^{35}$

\section{Toxicity}

The Achilles heel of the polymxyins is dose-limiting nephrotoxicity. There is a clear need to develop less nephrotoxic analogues, thereby allowing the use of higher doses to maximise efficacy and minimise the development of resistance. A number of reports have indicated that the reduction of positive charge renders polymyxins less toxic. ${ }^{15,60}$ Considering the octapeptins possess one less positive charge than the polymyxins (i.e $4 \mathrm{vs}$. 5, respectively), assessments of whether octapeptins display a polymyxin-like dose-dependent nephrotoxicity 
would be most worthwhile. Acute toxicity assessments in mice by the Bristol-Myers Company showed that the octapeptin $\mathrm{Bu}-1880$ and octapeptin $\mathrm{C}_{3}$ are less toxic than colistin via both intravenous and subcutaneous routes of administration. ${ }^{27,31,34}$ Interestingly, the des-fatty acyl octapeptin $\mathrm{C}_{2}$ was found to be less toxic than colistin by the intravenous route but more toxic subcutaneously. Moreover, the acute toxicity of octapeptin $\mathrm{C}_{2}$, was comparable to octapeptin $\mathrm{C}_{3}$ when administered intravenously, but octapeptin $\mathrm{C}_{2}$ was 5 -fold more toxic than octapeptin $\mathrm{C}_{3}$ subcutaneously; this would suggest the fatty acyl portion contributes to a depot effect in animals. ${ }^{27,34}$

In mouse acute toxicity studies octapeptin $\mathrm{B}_{5}$ show an $\mathrm{LD}_{50}$ of $15.46 \mathrm{mg} / \mathrm{kg}$ which was less toxic than the comparator polymyxin $\mathrm{B}\left(\mathrm{LD}_{50} 6.52 \mathrm{mg} / \mathrm{kg}\right){ }^{38}$ Octapeptin $\mathrm{B}_{5}$ was shown to exhibit negligible hemolysis of human and mouse blood cells and no toxicity aganst HEK293 cell up to concentrations of $128 \mathrm{mg} / \mathrm{L} .{ }^{35,}{ }^{38}$ However, the analogs of octapeptin $\mathrm{B}_{5}$ with $N$-termini substituted with very hydrophobic Fmoc or myristyl groups showed significantly increased hemolytic activity. ${ }^{35}$

\section{Biosynthesis}

The enormous structural and functional diversity of polymyxin-like lipopeptides is attributable to their nonribosomal mode of biosynthesis by large multifunctional enzymes termed non-ribosomal peptide synthetases (NRPS). NRPS enzymes function as natures specialized peptide assembly lines. NRPS are composed of semi-autonomous modular units, which in turn are composed of homologous catalytic domains. ${ }^{61}$ The order of these modules is co-linear with the sequence of the peptide product, such that the repeating series of modules forms an ordered macromolecular assembly line (Figure 3). Our group characterized the first sequence of an octapeptin biosynthetic cluster from the octapeptin $\mathrm{C} 4$ producer Bacillus circulans ATCC 31805 (unpublished results). The assembly of the octapeptin $\mathrm{C} 4$ peptide backbone involves three different nonribosomal peptide synthetise (NRPS) systems, OctA, OctB and OctC (Figure 3). The OctA NRPS is composed of three semi-autonomous modular units, which are in turn composed of homologous domains responsible for the activation and polymerisation of the first three constituent amino acids, Dab1-Dab2-Dab3 of the octapeptin peptide core. This tri-peptide is then translocated to the next NRPS, OctB which has four modules that incorporate Phe4-Leu5-Dab6-Dab7 into the growing peptide. The peptide is finally translocated to OctC where it receives the last amino acid Leu8, then is cyclized and concomitantly released by the terminal thioesterase-like (TE) domain on OctC. The three individual NRPS enzymes come together during lipopeptide assembly to form an ordered assembly line. Every module is composed of homologous domains responsible for the activation, modification and polymerisation of the constituent amino acids of octapeptin. The basic modular unit consists of catalytic domains responsible for substrate amino acid activation (A-domain, $~ 500$ amino acids), a Thiolation domain ( $T$, $\sim 80-100$ amino acids) which acts to translocate the $4^{\prime}$-phosphopantetheine ( $4^{\prime}$-Ppant) covalently tethered peptidyl chain intermediate between modular active sites, and a condensation (C-domain, $\sim 450$ amino acids) responsible for amide bond formation. In addition to these fundamental domain, some module may harbor auxiliary domain that perform specialized functions such as Epimerization domains (E) (seen in module 6 of OctA) that catalyze the generation of D-configured amino acids from the corresponding L- 
isomers when attached to the 4 '-Ppant; Thio-Esterase domains (TE, 280 amino acids; seen in module 10 of $\mathrm{OctC}){ }^{61}$ During the synthesis of non-ribosomal peptides, the growing peptide-chain is transferred from one module to the next, such that the growth of the octapeptin peptide occurs by an ordered succession of transpeptidation and condensation reactions. The consummation of octapeptin assembly results in the release of the mature peptide by ring closure catalyzed by a TE-domain situated at the extreme $\mathrm{C}$ terminus of the last module of OctC. The lipidation of octapeptin peptide core with the $\mathrm{N}$-terminal hydroxyl-fatty acyl chain possibly occurs post-assembly and is likely mediated by as yet uncharacterized external fatty acyl ligase enzymes.

The smaller octapeptin NRPS cluster contrasts the larger polymxyin NRPS gene cluster which consists of five open reading frames, $m_{x} A, p m x B, p m x C, p m x D$ and $p m x E$ (Figure 3 ). Three of the genes $p m x A, p m x B$ and $p m x E$ are NRPS directly involved in polymyxin synthesis, while $p m x C$ and $p m x D$ encode self-resistance $\mathrm{ABC}$ transporters responsible for export of the lipopeptide out of the cell. The sequence $\operatorname{pmx} A(15 \mathrm{~kb})$ encodes for a synthetase of 4,998 amino acids, $p m x B(3.3 \mathrm{~kb})$ encodes for a synthetase of 1,102 amino acids and $p m x E(18.9 \mathrm{~kb})$ encodes for a synthetase of 6,292 amino acids. The three NRPSs (PmxA, PmxB, and PmxE) contain different numbers of modules, PmxB is a single module NRPS, PmxA is composed of four modules and PmxE of five modules.

From comparisons with the larger polymxyin B NRPS cluster it becomes obvious that the octapeptin NRPS evolved through module deletion events or visa versa the polymyxin NRPS cluster evolved through deletion events. It is tenable to imagine that in order to achieve killing of polymyxin-resistant Gram-negative and Gram-positive bacteria which were competing for nutrients in its environment, Bacillus circulans has evolved the octapeptin core scaffold through module swapping and deletion events of its nonribosomal biosynthetic machinery. ${ }^{62,63}$ Whereas, the polymyxin producing Bacillus polymyxa may not have encountered Gram-positive competition, and hence did not have a need to diversify the polymyxin core scaffold to increase its antimicrobial spectrum beyond Gram-negatives. This would make sense given that they are both the polymyxins and octapeptins are produced by closely related Bacillus spp. ${ }^{62,63}$ In line with this theory, the aforementioned mode of action studies suggest that octapeptins have retained the polymyxin-like ability to bind to lipid A (a Gram-negative specific outer membrane component), whilst having developed the extra ability to bind to bacterial phospholipids, which endows them with a broader spectrum of activity against Gram-positives and yeast.

\section{Outlook}

There is a critical requirement for new antibacterial agents to meet growing unmet treatment needs especially in the hospital setting. The time has come for a global commitment to develop new antibiotics. The octapeptins have superior antimicrobial activity against polymyxin-resistant XDR Gram-negative and Gram-positive bacteria and appear to have improved pharmacological profiles compared to the 'last-line' polymyxin B and colistin. Based on their higher order activity, lack of cross-resistance and apparent lower toxicity, octapeptins represent viable clinical candidates. The fact that octapeptins are produced by Bacillus circulans via non-ribosomal template driven synthesis makes future biosynthetic 
approaches aimed at generating therapeutics highly amenable to recombinant technologies. Overall, this review highlights the benefits and caveats underpinning the foundations for the re-development of octapeptins as a new-generation of lipopeptide antibiotics to treat lifethreatening infections caused by 'superbugs'.

\section{Acknowledgments}

T. V. and J. L. are supported by the National Institute of Allergy and Infectious Diseases of the National Institutes of Health (R01 AI111965 and AI098771). The content is solely the responsibility of the authors and does not necessarily represent the official views of the National Institutes of Health. J.L. is an Australian NHMRC Senior Research Fellow. T.V. is an Australian NHMRC Industry Career Development Research Fellow.

\section{References}

1. Ventola CL. P T. 2015; 40:277-283. [PubMed: 25859123]

2. C. f. D. C. a. Prevention. Antibiotic resistance threats in the United State. 2013.

3. Shlaes, DM. Antibiotics. 2010. p. 97-99.

4. Shlaes DM, Spellberg B. Curr Opin Pharmacol. 2012; 12:522-526. [PubMed: 22832234]

5. IDSA. [last accessed on April 29, 2008] Bad bugs, no drugs. http://www.idsociety.org/ badbugsnodrugs.html

6. Journal, 2013

7. Clardy J, Fischbach MA, Currie CR. Curr Biol. 2009; 19:R437-441. [PubMed: 19515346]

8. Brown JM. J S C Med Assoc. 2001; 97:38-39. [PubMed: 11227256]

9. McGraw DJ. Bull Bibliogr. 1986; 43:103-107. [PubMed: 11616715]

10. Zapor MJ, Erwin D, Erowele G, Wortmann G. Infect Control Hosp Epidemiol. 2008; 29:661-663. [PubMed: 18593337]

11. van Veen HW, Margolles A, Putman M, Sakamoto K, Konings WN. Antonie Van Leeuwenhoek. 1999; 76:347-352. [PubMed: 10532389]

12. Poole K. Curr Opin Microbiol. 2001; 4:500-508. [PubMed: 11587924]

13. Nikaido H. Annu Rev Biochem. 2009; 78:119-146. [PubMed: 19231985]

14. Talbot GH, Bradley J, Edwards JE Jr, Gilbert D, Scheld M, Bartlett JG. Clin Infect Dis. 2006; 42:657-668. [PubMed: 16447111]

15. Velkov T, Thompson PE, Nation RL, Li J. J Med Chem. 2010; 53:1898-1916. [PubMed: 19874036]

16. Meyers E, Brown WE, Principe PA, Rathnum ML, Parker WL. J Antibiot (Tokyo). 1973; 26:444448. [PubMed: 4209531]

17. Meyers E, Pansy FE, Basch HI, McRipley RJ, Slusarchyk DS, Graham SF, Trejo WH. J Antibiot (Tokyo). 1973; 26:457-462. [PubMed: 4209832]

18. Meyers E, Parker WL, Brown WE, Linnett P, Strominger JL. Ann N Y Acad Sci. 1974; 235:493501. [PubMed: 4368713]

19. Parker WL, Rathnum ML. J Antibiot (Tokyo). 1973; 26:449-456. [PubMed: 4792068]

20. Parker WL, Rathnum ML. J Antibiot (Tokyo). 1975; 28:379-389. [PubMed: 170240]

21. Puar MS. J Antibiot (Tokyo). 1980; 33:760-763. [PubMed: 7410218]

22. Rosenthal KS, Ferguson RA, Storm DR. Antimicrob Agents Chemother. 1977; 12:665-672. [PubMed: 931364]

23. Rosenthal KS, Swanson PE, Storm DR. Biochemistry. 1976; 15:5783-5792. [PubMed: 188442]

24. Shoji J, Sakazaki R, Wakisaka Y, Koizumi K, Matsuura S, Miwa H, Mayama M. J Antibiot (Tokyo). 1980; 33:182-185. [PubMed: 7380726]

25. Sugawara K, Yonemoto T, Konishi M, Matsumoto K, Miyaki T, Kawaguchi H. J Antibiot (Tokyo). 1983; 36:634-638. [PubMed: 6874584]

26. Kato T, Shoji T. J Antibiot (Tokyo). 1980; 33:186-191. [PubMed: 7380727] 
27. Konishi M, Sugawara K, Tomita K, Matsumoto K, Miyaki T, Fujisawa K, Tsukiura H, Kawaguchi H. J Antibiot (Tokyo). 1983; 36:625-633. [PubMed: 6874583]

28. Qian CD, Wu XC, Teng Y, Zhao WP, Li O, Fang SG, Huang ZH, Gao HC. Antimicrob Agents Chemother. 2012; 56:1458-1465. [PubMed: 22183171]

29. Shoji J, Hinoo H, Wakisaka Y, Koizumi K, Mayama M. J Antibiot (Tokyo). 1976; 29:516-520. [PubMed: 956039]

30. Storm DR, Rosenthal KS, Swanson PE. Annu Rev Biochem. 1977; 46:723-763. [PubMed: 197881]

31. Kawaguchi H, Tsukiura H, Fujisawa KI, Numata KI. Journal. 1975

32. Makimura Y, Asai Y, Sugiyama A, Ogawa T. J Med Microbiol. 2007; 56:1440-1446. [PubMed: 17965342]

33. Sidorczyk Z, Zahringer U, Rietschel ET. Eur J Biochem. 1983; 137:15-22. [PubMed: 6360683]

34. Konishi M, Sugawara K, Tomita K, Matsumoto K, Miyaki T, Fujisawa K, Tsukiura H, Kawaguchi H. Journal of Antibiotics. 1983; 36:625-633. [PubMed: 6874583]

35. De Zoysa GH, Cameron AJ, Hegde VV, Raghothama S, Sarojini V. Journal of Medicinal Chemistry. 2015; 58:625-639. [PubMed: 25495219]

36. HGaS, De Zoysa V. Chemistry in New Zealand. 2015 Apr.:94-101.

37. Meyers E, Pansy FE, Basch HI, McRipley RJ, Slusarch Ds, Graham SF, Trejo WH. Journal of Antibiotics. 1973; 26:457-462. [PubMed: 4209832]

38. Qian C-D, Wu X-C, Teng Y, Zhao W-P, Li O, Fang S-G, Huang Z-H, Gao H-C. Antimicrobial Agents and Chemotherapy. 2011 published ahead of print, 19 Dec.

39. Nikaido H. Microbiol Mol Biol Rev. 2003; 67:593-656. [PubMed: 14665678]

40. Hancock RE. J Med Microbiol. 1997; 46:1-3. [PubMed: 9003734]

41. Hancock RE. Lancet. 1997; 349:418-422. [PubMed: 9033483]

42. Hancock RE. Trends Microbiol. 1997; 5:37-42. [PubMed: 9025234]

43. Hancock RE, Lehrer R. Trends Biotechnol. 1998; 16:82-88. [PubMed: 9487736]

44. Velkov T, Thompson PE, Nation RL, Li J. J Med Chem. 53:1898-1916.

45. Gunn JS. Trends Microbiol. 2008; 16:284-290. [PubMed: 18467098]

46. Gunn JS, Lim KB, Krueger J, Kim K, Guo L, Hackett M, Miller SI. Mol Microbiol. 1998; 27:1171-1182. [PubMed: 9570402]

47. Gunn JS, Ryan SS, Van Velkinburgh JC, Ernst RK, Miller SI. Infect Immun. 2000; 68:6139-6146. [PubMed: 11035717]

48. Schurek KN, Sampaio JL, Kiffer CR, Sinto S, Mendes CM, Hancock RE. Antimicrob Agents Chemother. 2009; 53:4345-4351. [PubMed: 19635950]

49. Shi Y, Cromie MJ, Hsu FF, Turk J, Groisman EA. Mol Microbiol. 2004; 53:229-241. [PubMed: 15225317]

50. Trent MS, Ribeiro AA, Lin S, Cotter RJ, Raetz CR. J Biol Chem. 2001; 276:43122-43131. [PubMed: 11535604]

51. Vaara M. Drugs Exp Clin Res. 1991; 17:437-443. [PubMed: 1822436]

52. Viljanen P, Vaara M. Antimicrob Agents Chemother. 1984; 25:701-705. [PubMed: 6331296]

53. Peterson AA, Fesik SW, McGroarty EJ. Antimicrob Agents Chemother. 1987; 31:230-237. [PubMed: 3032093]

54. Meyers E, Parker WL, Brown WE. J Antibiot (Tokyo). 1976; 29:1241-1242. [PubMed: 993110]

55. Koike M, Iida K, Matsuo T. J Bacteriol. 1969; 97:448-452. [PubMed: 4303542]

56. Swanson PE, Paddy MR, Dahlquist FW, Storm DR. Biochemistry. 1980; 19:3307-3314. [PubMed: 6250564]

57. LaPorte DC, Rosenthal KS, Storm DR. Biochemistry. 1977; 16:1642-1648. [PubMed: 192271]

58. Deris ZZ, Akter J, Sivanesan S, Roberts KD, Thompson PE, Nation RL, Li J, Velkov T. J Antibiot (Tokyo). 2013; 67:147-151. [PubMed: 24169795]

59. Shoji J, Hinoo H, Sakazaki R. J Antibiot (Tokyo). 1976; 29:521-525. [PubMed: 956040] 
60. Vaara M, Fox J, Loidl G, Siikanen O, Apajalahti J, Hansen F, Frimodt-Moller N, Nagai J, Takano M, Vaara T. Antimicrob Agents Chemother. 2008; 52:3229-3236. [PubMed: 18591267]

61. Velkov T, Lawen A. Biotechnol Annu Rev. 2003; 9:151-197. [PubMed: 14650927]

62. Park SY, Choi SK, Kim J, Oh TK, Park SH. Appl Environ Microbiol. 2010; 78:4194-4199.

63. Choi SK, Park SY, Kim R, Kim SB, Lee CH, Kim JF, Park SH. J Bacteriol. 2009; 191:3350-3358. [PubMed: 19304848] 


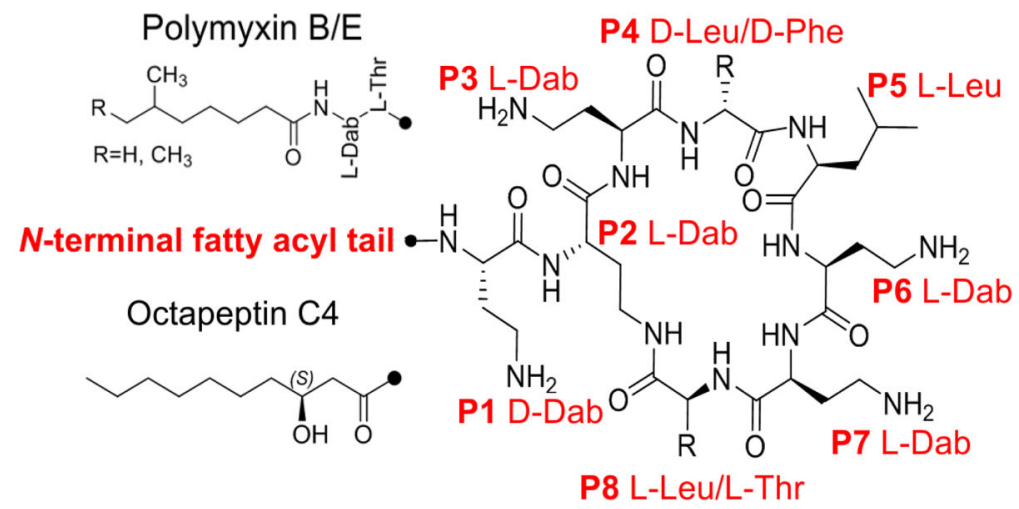

Figure 1.

The chemical structures of octapeptin $\mathrm{C} 4$ and polymyxin $\mathrm{B}_{1}$. Leu: leucine; Phe: phenylalanine; Dab: a, $\boldsymbol{\gamma}$-diaminobutyric acid. 


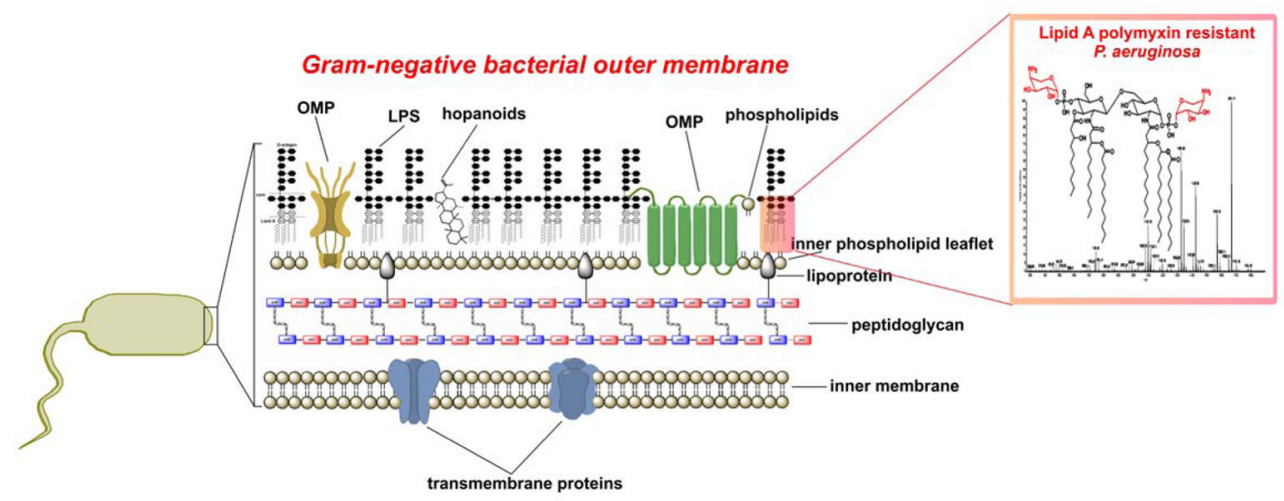

Figure 2.

Architecture of the Gram-negative bacterial outer membrane. 


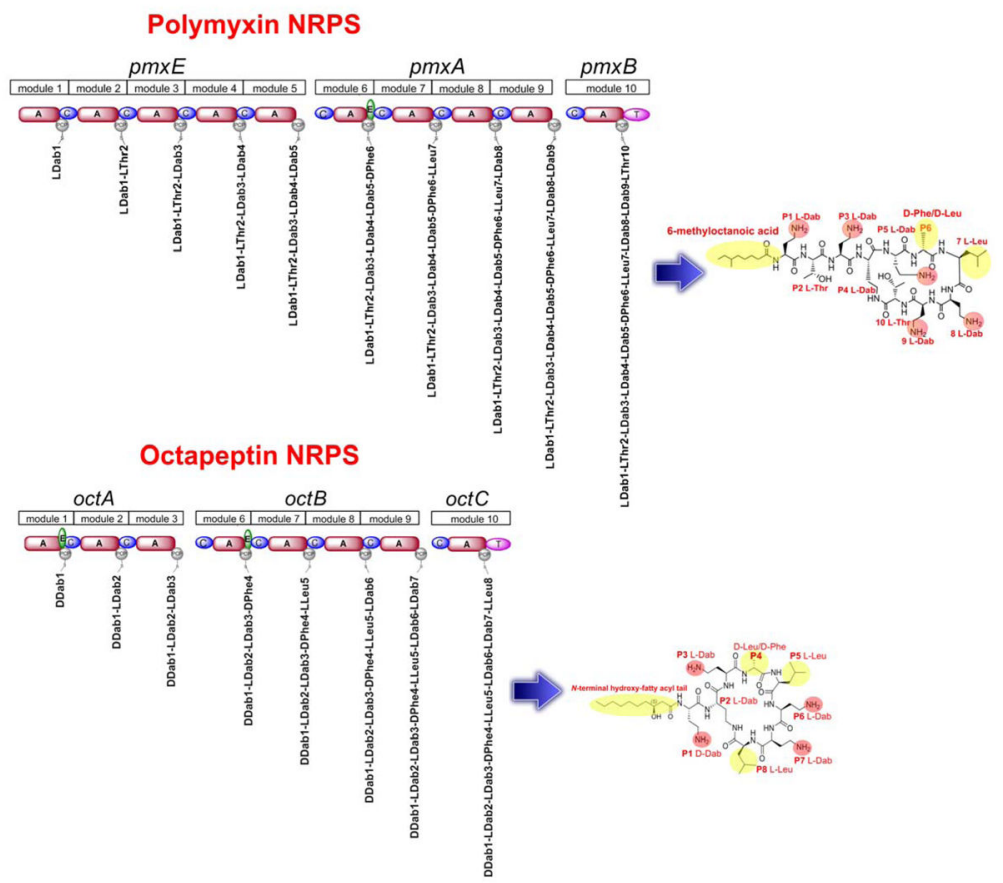

Figure 3.

Schematic of the polymyxin B and octapeptin C4 nonribosomal peptide synthetase biosynethtic clusters. These multi-enzyme complexes are composed of modules which contain domains that activate and incorporate the cognate amino acids of each lipopeptide. All modules contain condensation, adenylation (A) and peptidyl-carrier (PCP) and condensation (C) domains. Certain modules also contain an epimerization (E) domain and terminal modules contain a thioesterase domain (TE) which catalyzes the intra-molecular cyclization and release of the lipopeptide. 


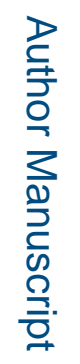

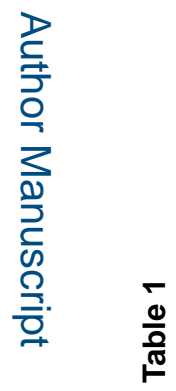

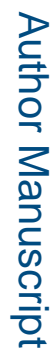

\begin{tabular}{|c|c|c|c|c|c|c|c|c|c|c|c|c|c|c|c|c|c|c|c|}
\hline & $\begin{array}{l}i n \\
0 \\
a \\
a\end{array}$ & 蛋 & 离 & 离 & 胥 & 总 & $\frac{g}{\frac{g}{S}}$ & \begin{tabular}{|c|}
0 \\
$\frac{g}{3}$ \\
1
\end{tabular} & $\mid \begin{array}{c}0 \\
\frac{D}{1} \\
-1\end{array}$ & $\begin{array}{l}\frac{D}{D_{1}} \\
\frac{1}{1}\end{array}$ & 离 & 离 & 离 & 童 & 韵 & 胥 & 童 & 离 & 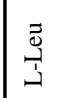 \\
\hline & $\begin{array}{l}\dot{v} \\
\ddot{v} \\
\stackrel{a}{2}\end{array}$ & 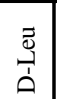 & 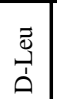 & 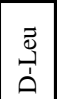 & 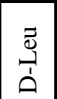 & 离 & 离 & 离 & 离 & 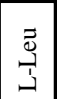 & $\begin{array}{l}\frac{g}{D} \\
\frac{1}{D}\end{array}$ & 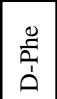 & $\frac{g}{D_{1}^{1}}$ & $\frac{g}{0}$ & $\frac{g}{0}$ & 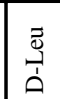 & 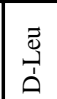 & $\mid$\begin{tabular}{l}
$\bar{z}$ \\
\multirow{1}{*}{} \\
0
\end{tabular} & فㄹ \\
\hline 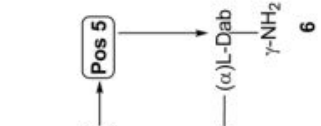 & $\begin{array}{l}\overline{v_{0}} \\
\stackrel{a}{a}\end{array}$ & $\begin{array}{l}\text { 苋 } \\
\stackrel{1}{0}\end{array}$ & 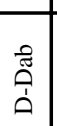 & 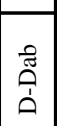 & 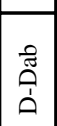 & $\begin{array}{l}\text { न } \\
\text { คी }\end{array}$ & $\begin{array}{l}\text { Фี } \\
\text { คิ }\end{array}$ & 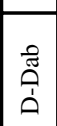 & 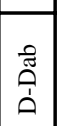 & 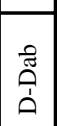 & 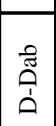 & $\begin{array}{l}\text { مी } \\
\text { คิ }\end{array}$ & $\begin{array}{l}\text { त्ञ } \\
\text { مी }\end{array}$ & $\begin{array}{l}\text { 華 } \\
\text { คे }\end{array}$ & 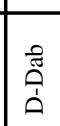 & $\begin{array}{l}\vec{u} \\
\tilde{n} \\
\dot{n}\end{array}$ & $\mid \begin{array}{l}\tilde{u} \\
\tilde{n} \\
\dot{n}\end{array}$ & $\mid \begin{array}{l}\bar{d} \\
\omega \\
\omega\end{array}$ & 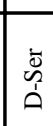 \\
\hline 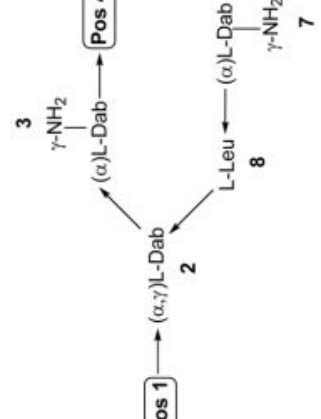 & 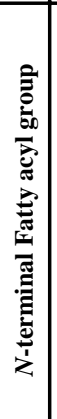 & 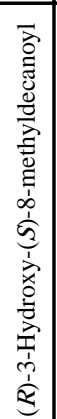 & 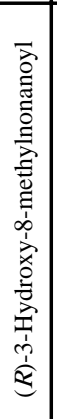 & 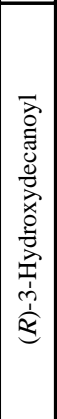 & 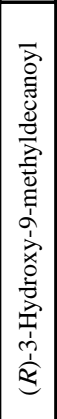 & 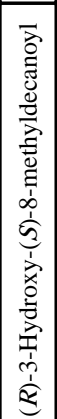 & 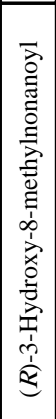 & 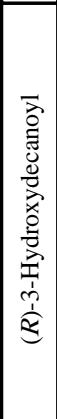 & 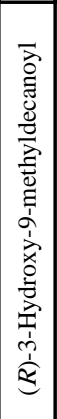 & 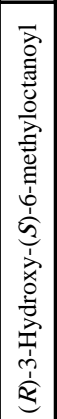 & $I$ & 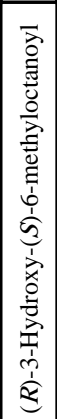 & 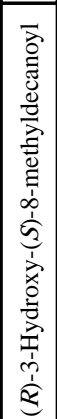 & 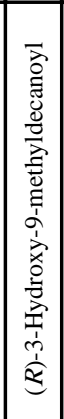 & 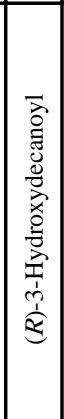 & 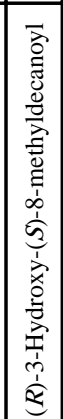 & 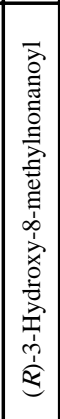 & 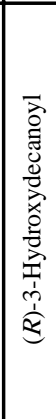 & 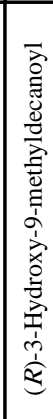 \\
\hline 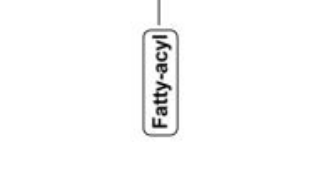 & 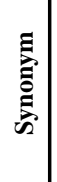 & $\sum_{i=1}^{\infty}$ & 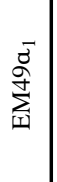 & $\sum_{i=i}^{\delta}$ & & $\sum_{i=1}^{\infty}$ & 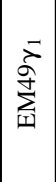 & 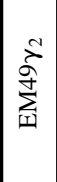 & ' & 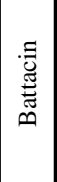 & 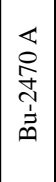 & 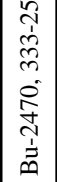 & $\begin{array}{l}\overrightarrow{0} \\
\stackrel{2}{a} \\
\stackrel{+}{1} \\
\dot{n}\end{array}$ & 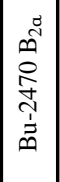 & 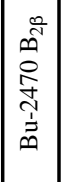 & & & & \\
\hline & 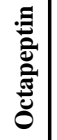 & 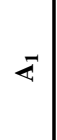 & ष & 4 & Z & $\hat{\theta}$ & $\approx^{-1}$ & 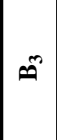 & $\vec{A}$ & $\approx$ & $0^{0}$ & $\widetilde{J}$ & v & $0^{\infty}$ & $U^{*}$ & $=$ & $\Omega$ & $\Omega$ & $0^{+}$ \\
\hline
\end{tabular}

Nat Prod Rep. Author manuscript; available in PMC 2018 March 17. 

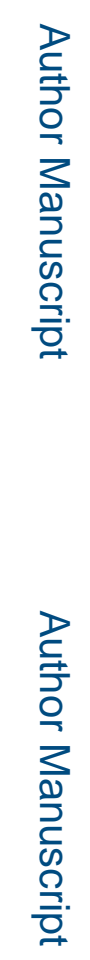

:

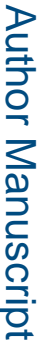

$\frac{D}{c}$
$\frac{1}{2}$
$\frac{1}{2}$
$\frac{1}{2}$
$\frac{2}{0}$
$\frac{\rho}{0}$
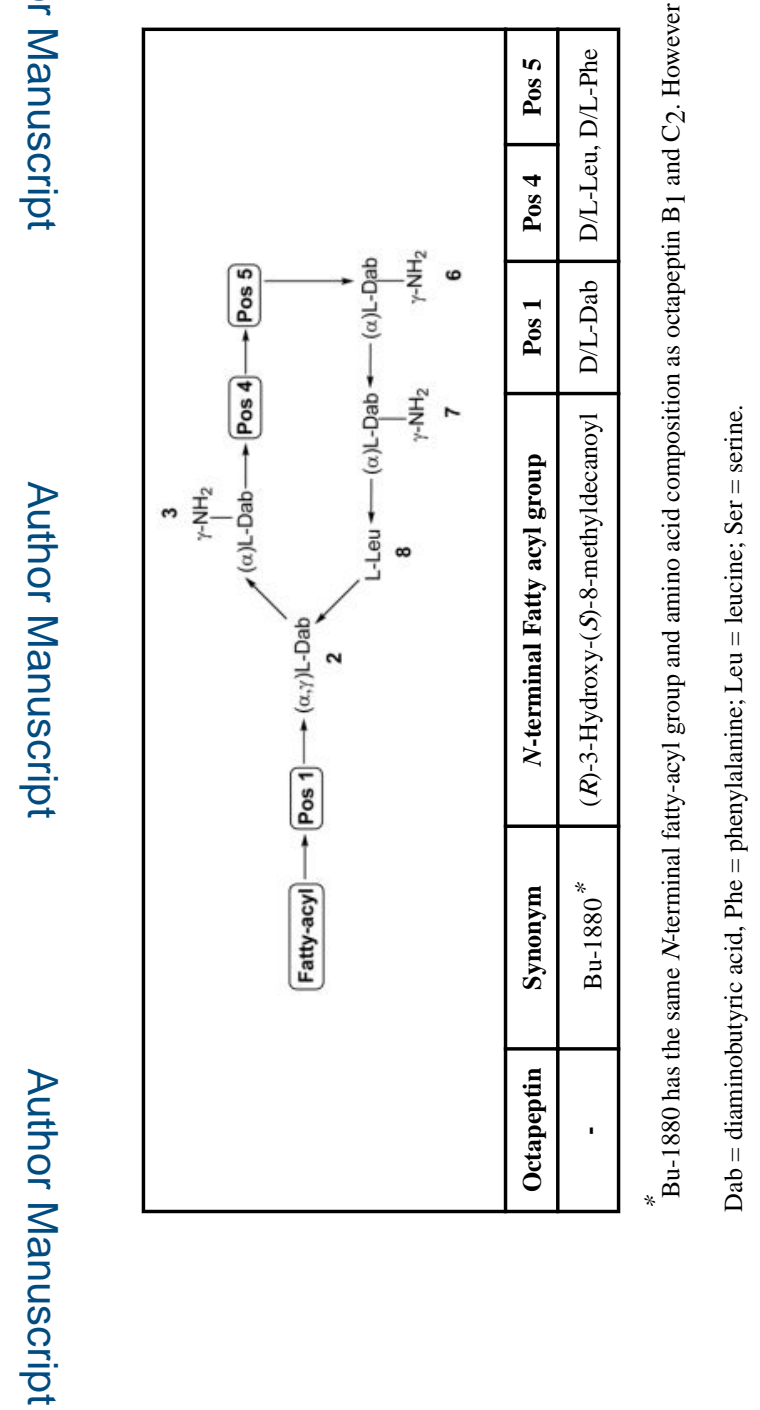

Nat Prod Rep. Author manuscript; available in PMC 2018 March 17. 


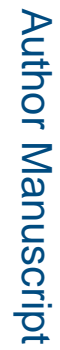

롤

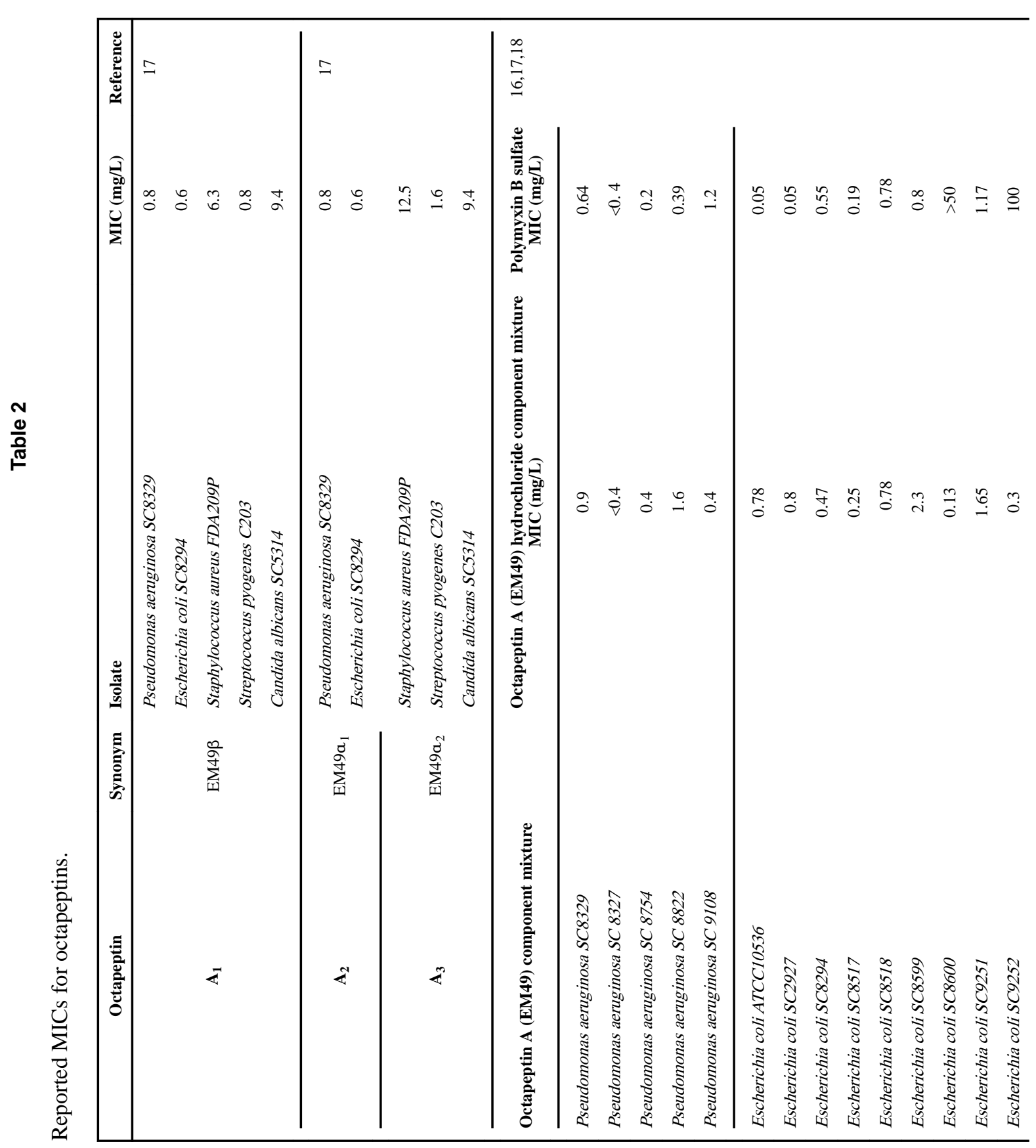

Nat Prod Rep. Author manuscript; available in PMC 2018 March 17. 


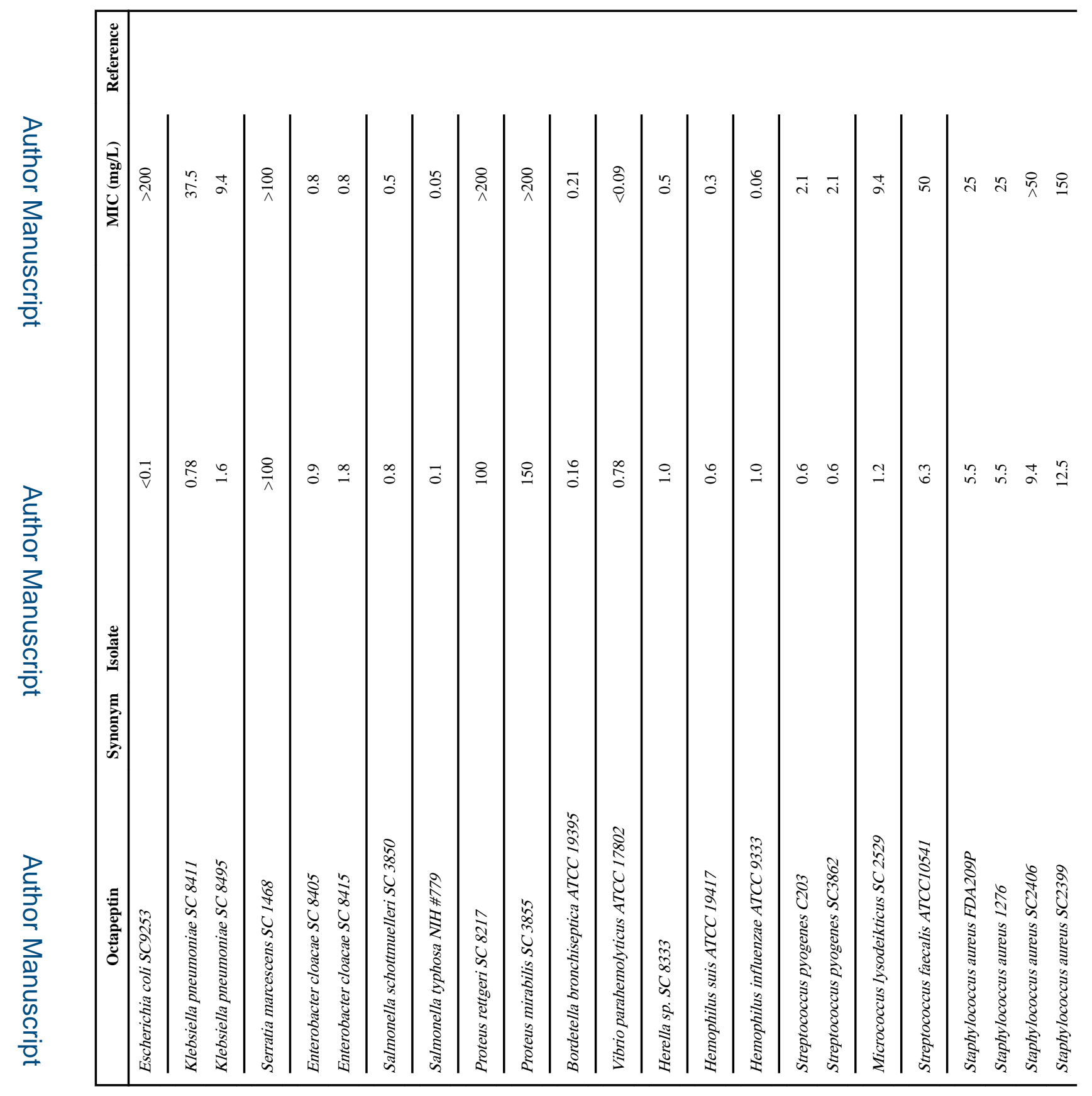

로을 


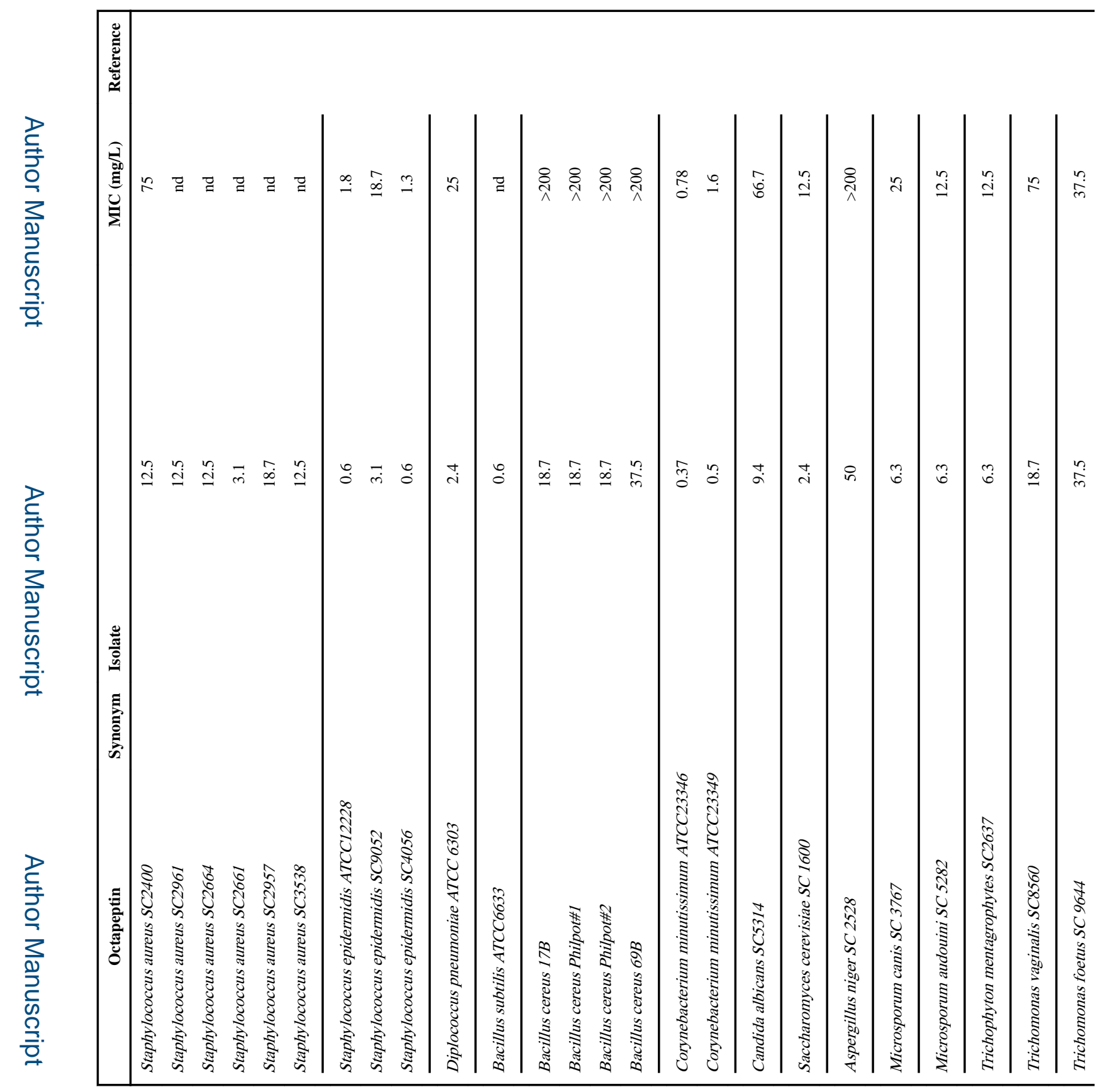

로을 


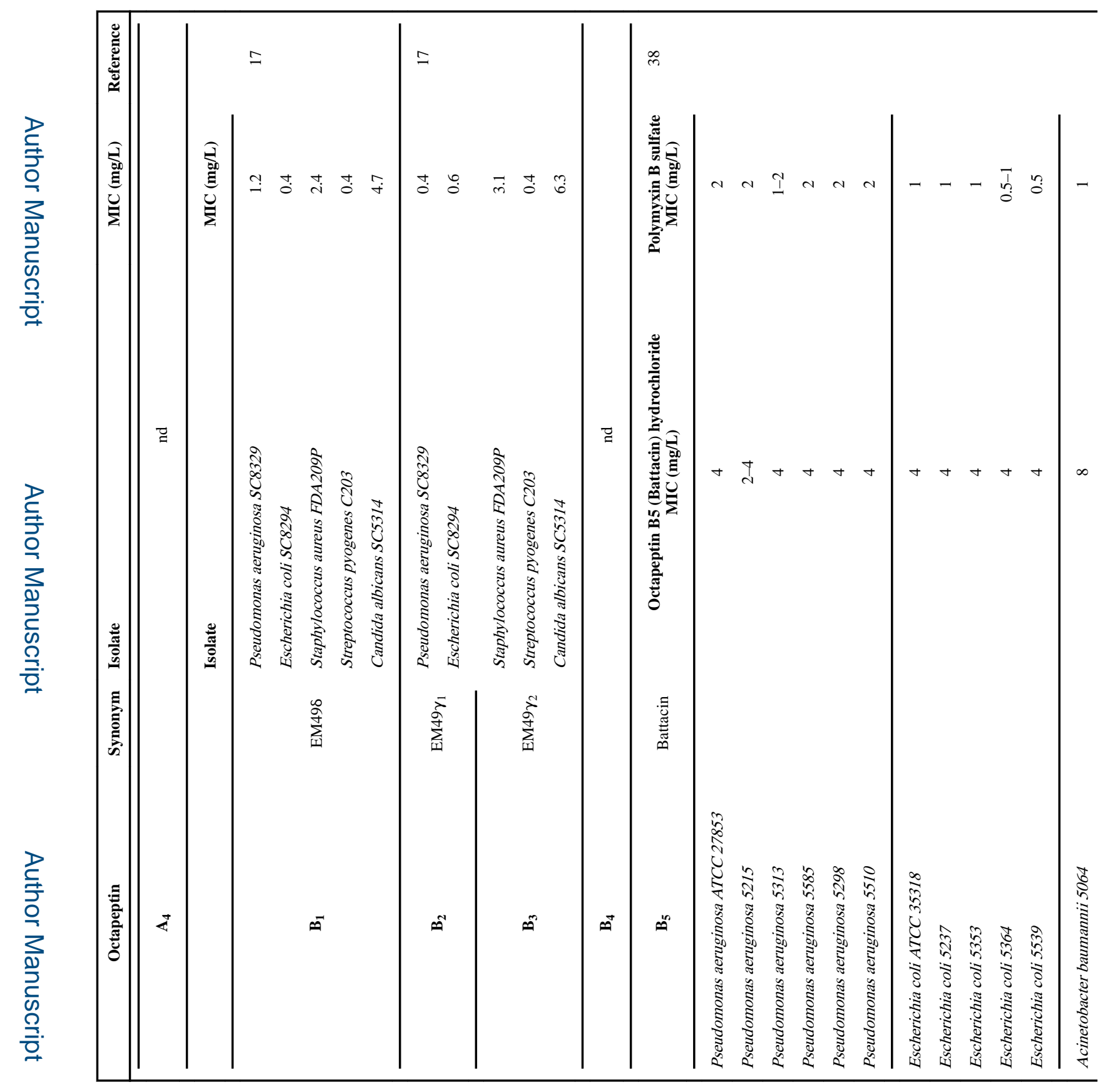

로을 


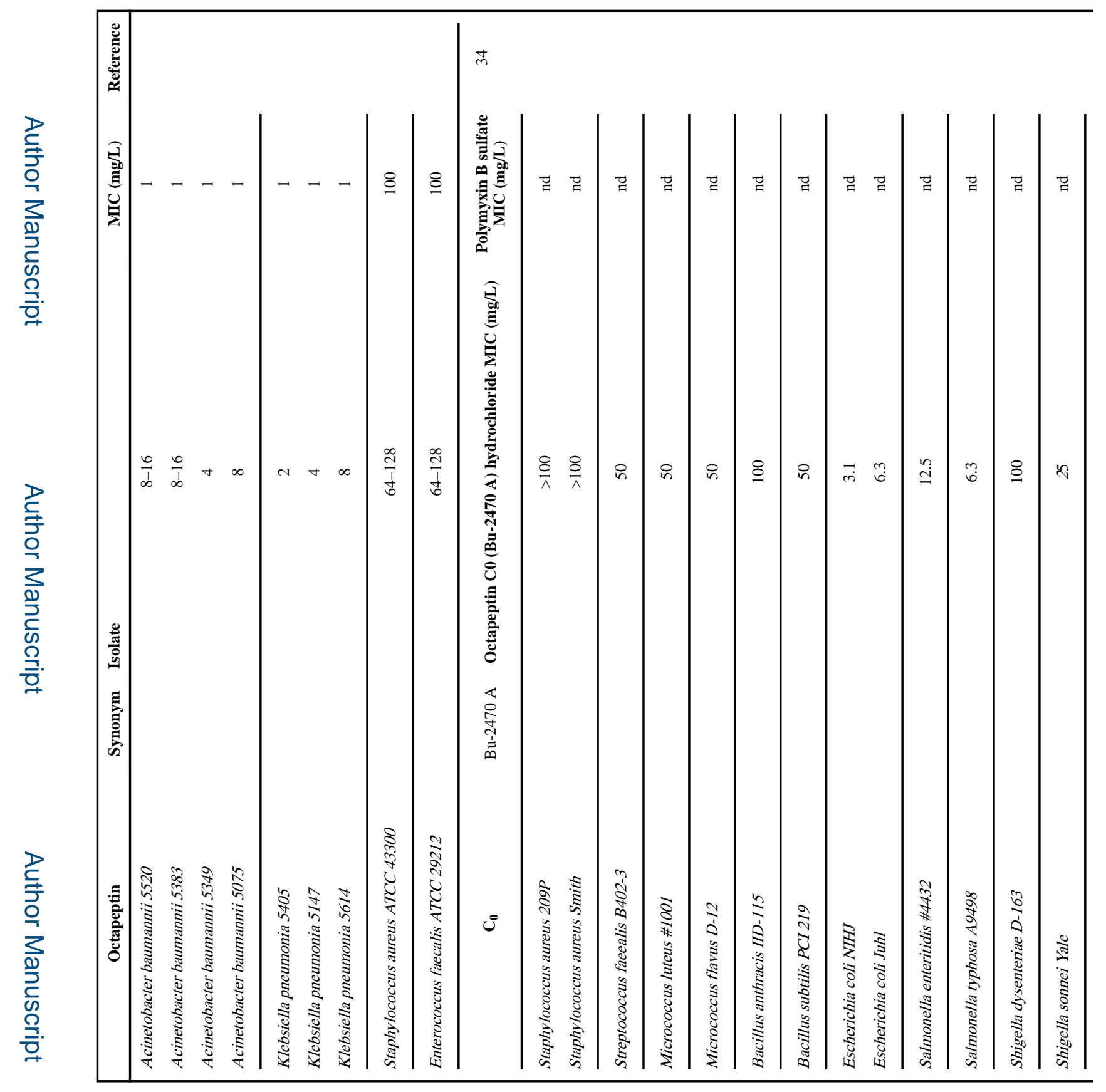

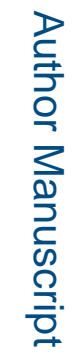




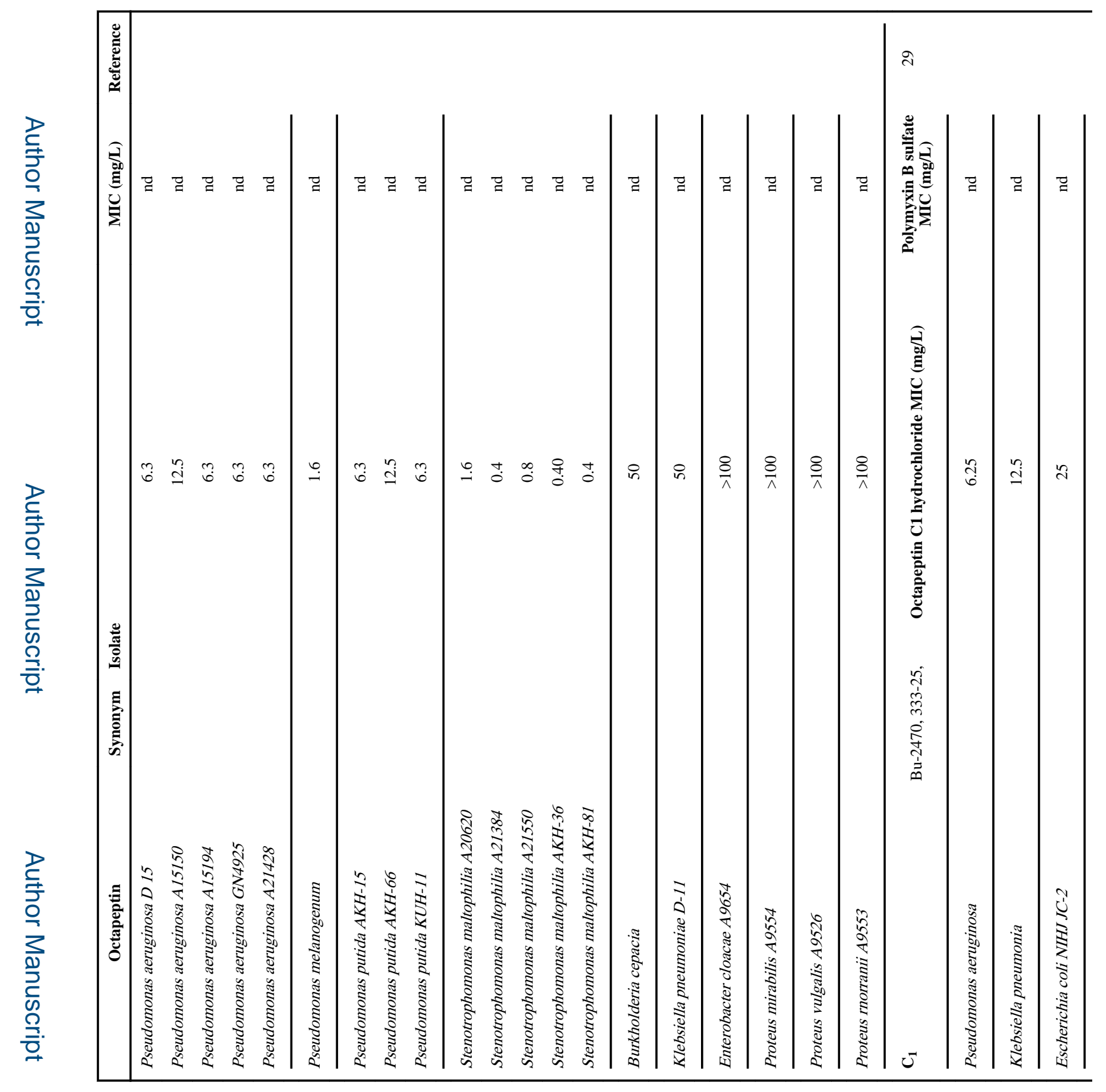

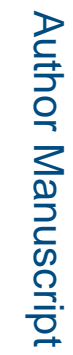




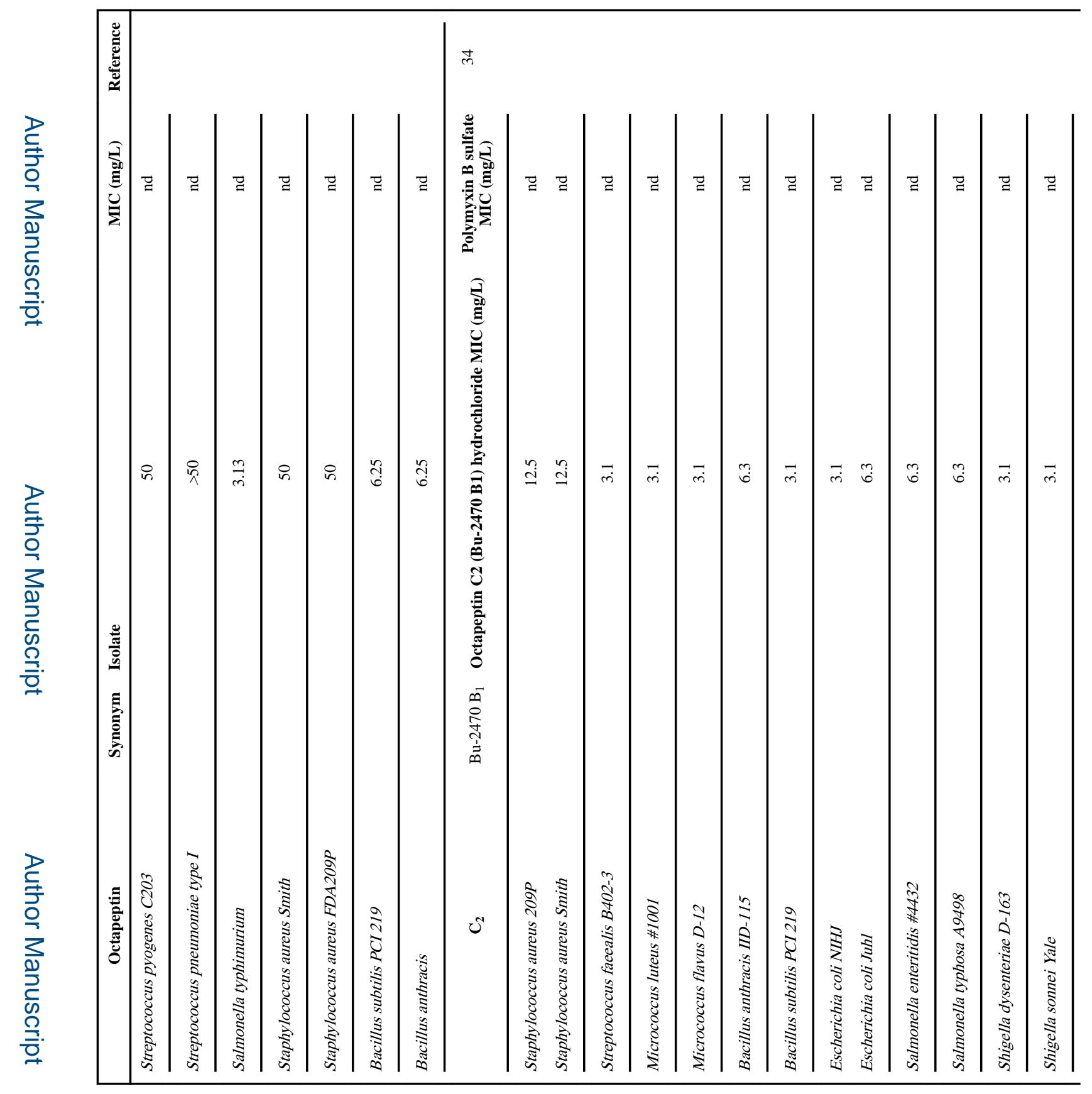

로을 


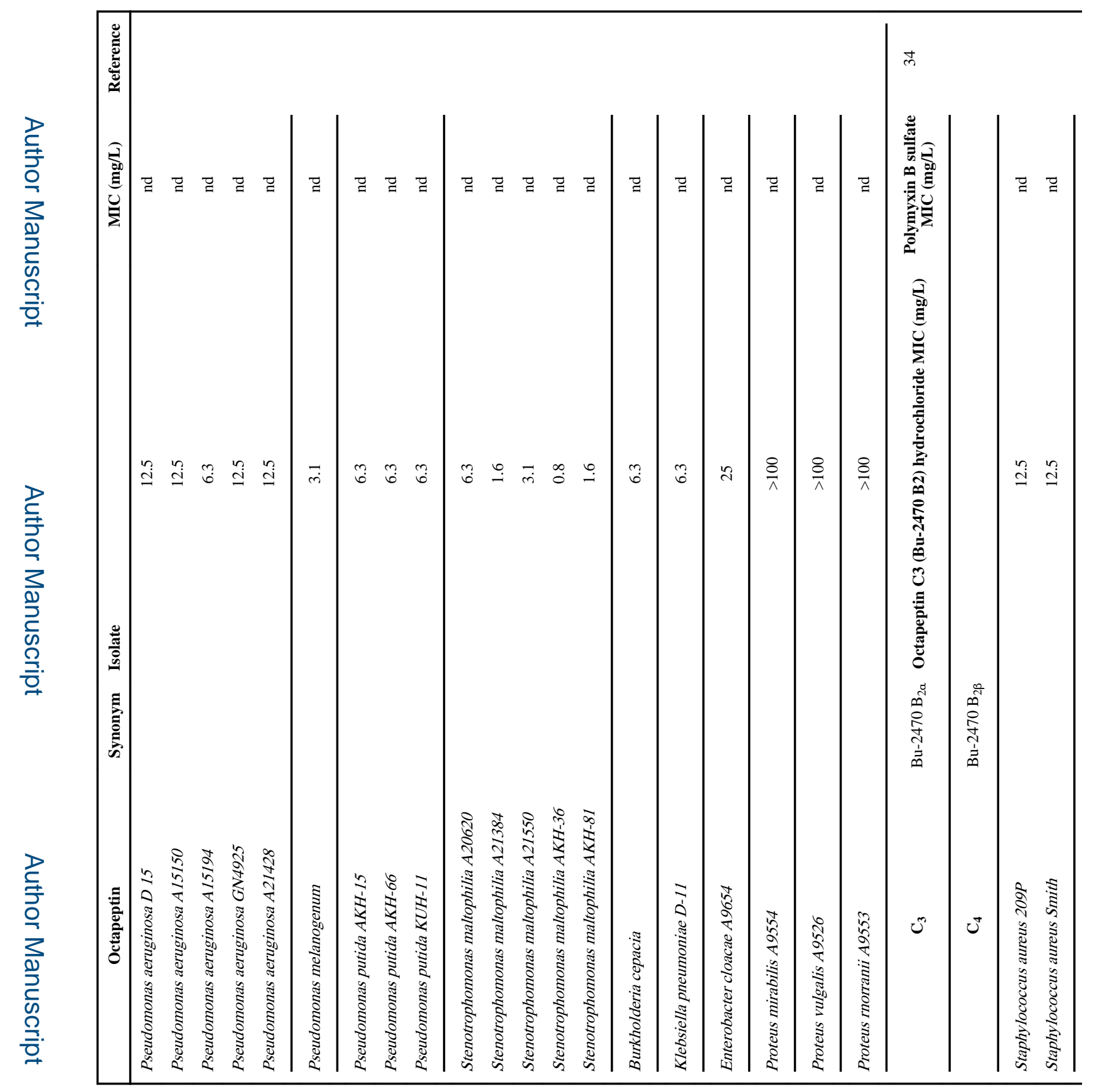

로을 


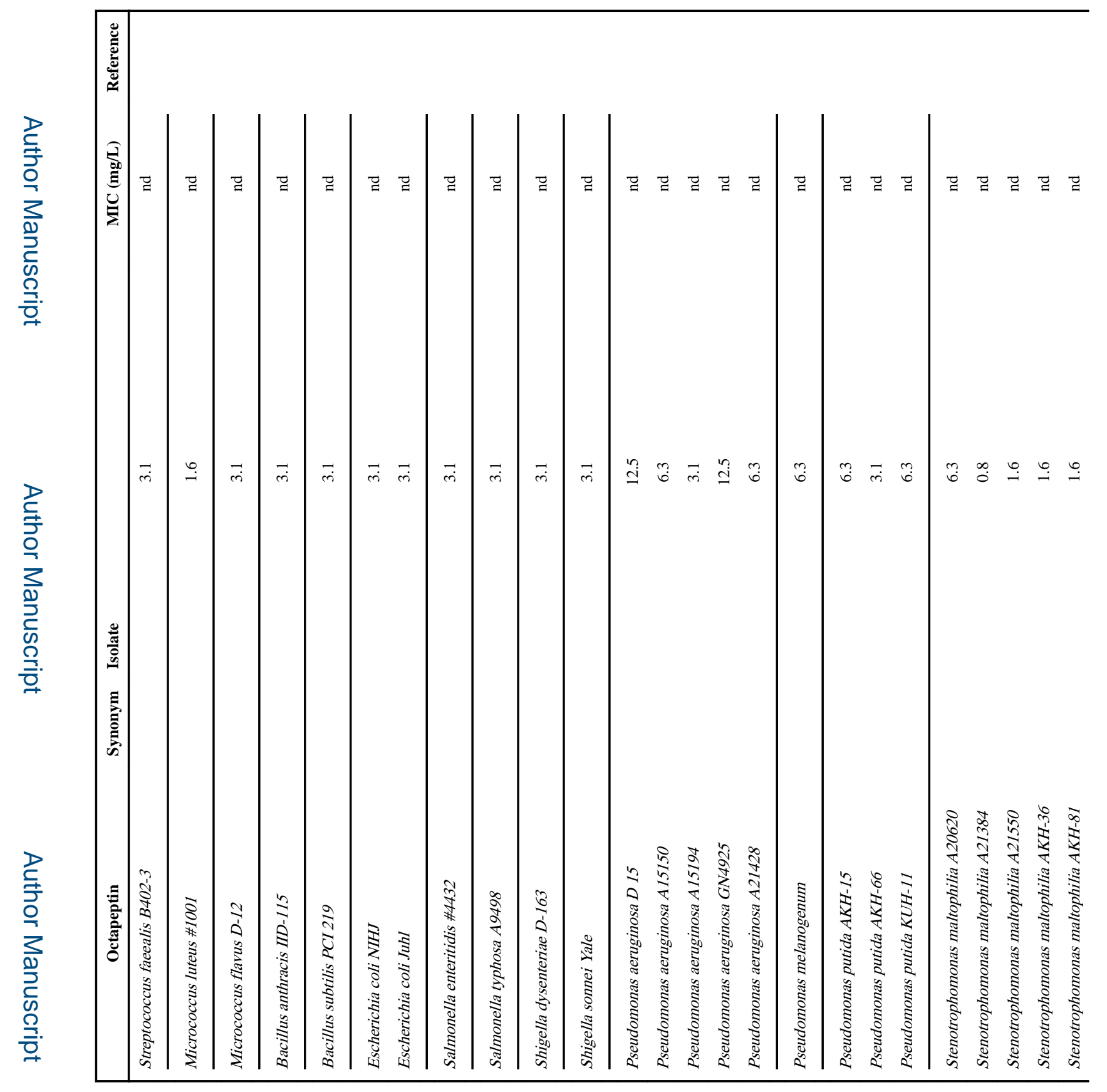

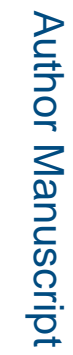




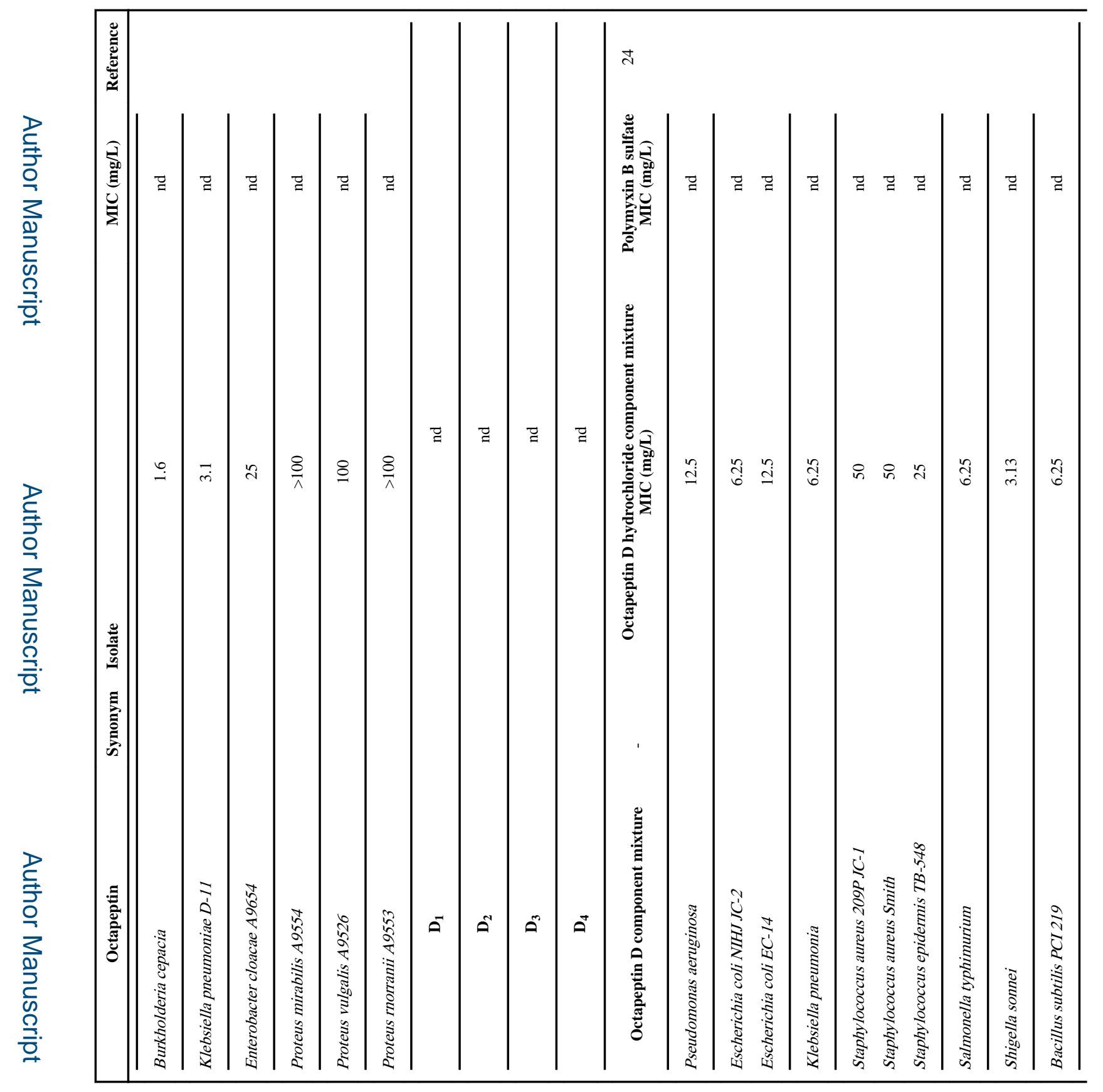

로을 


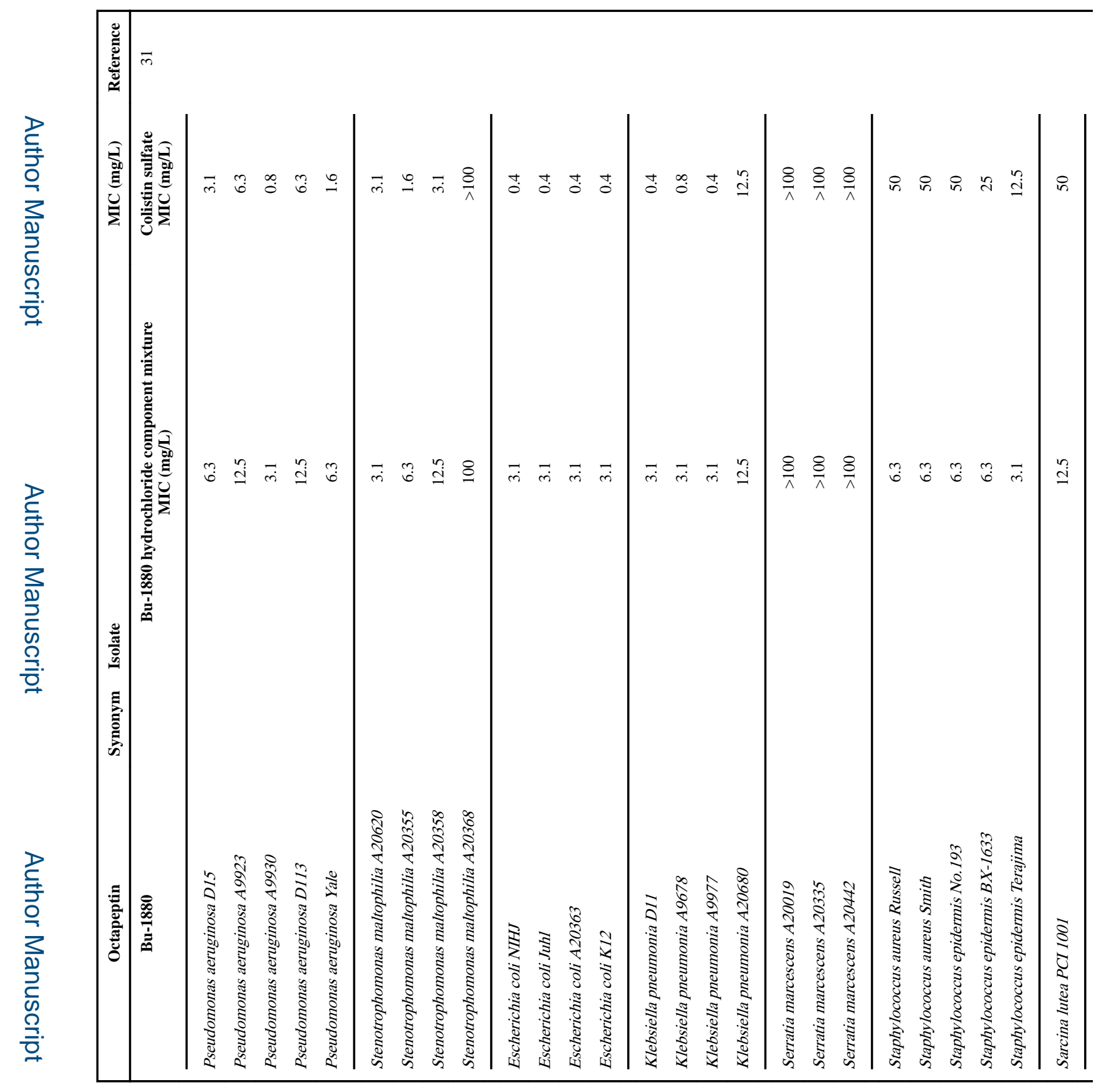

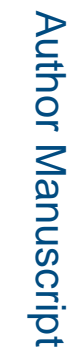




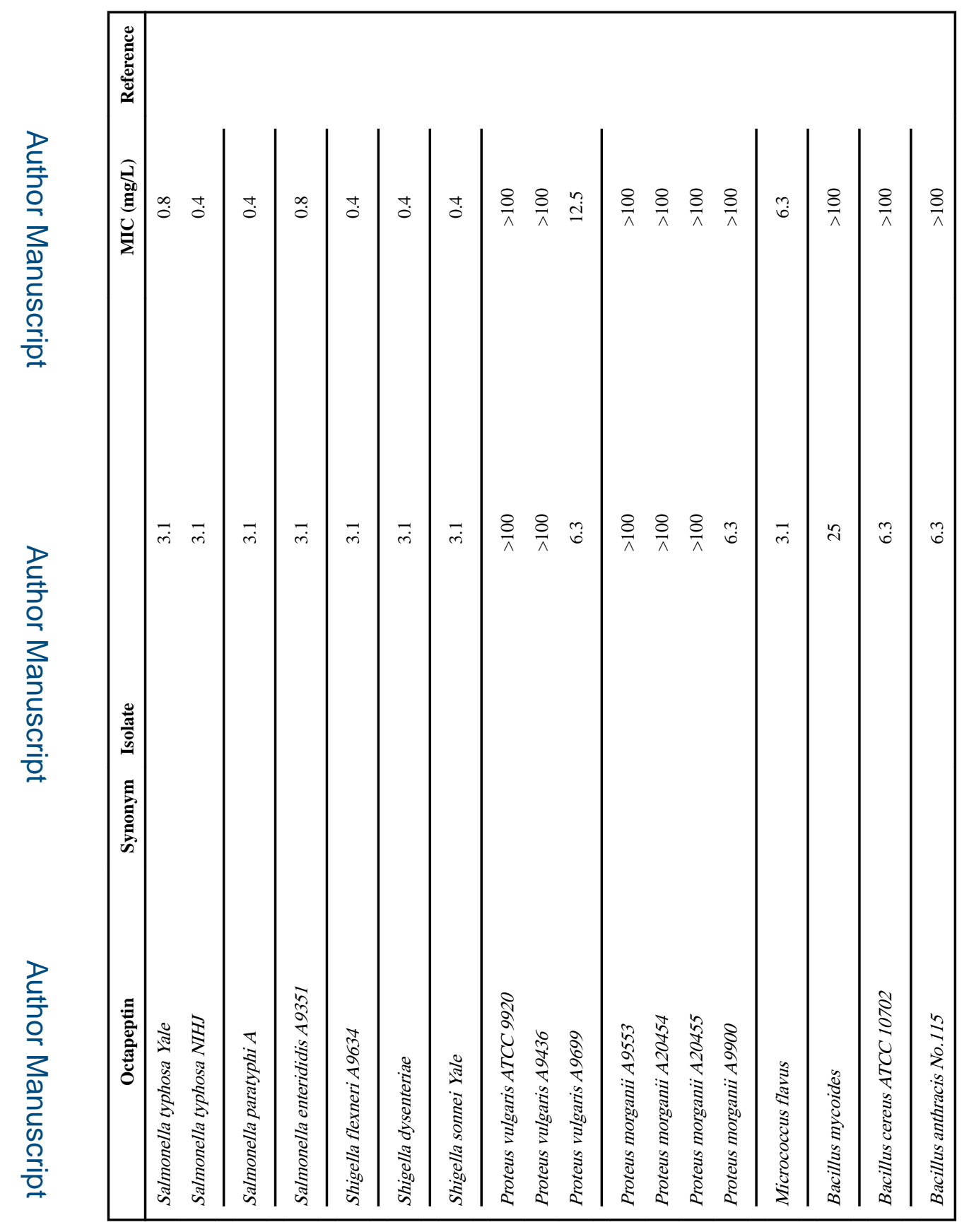

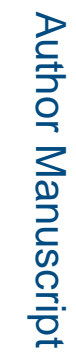

